\title{
Biobased Plastics 2020
}

KARIN MOLENVELD AND HARRIËTte BoS

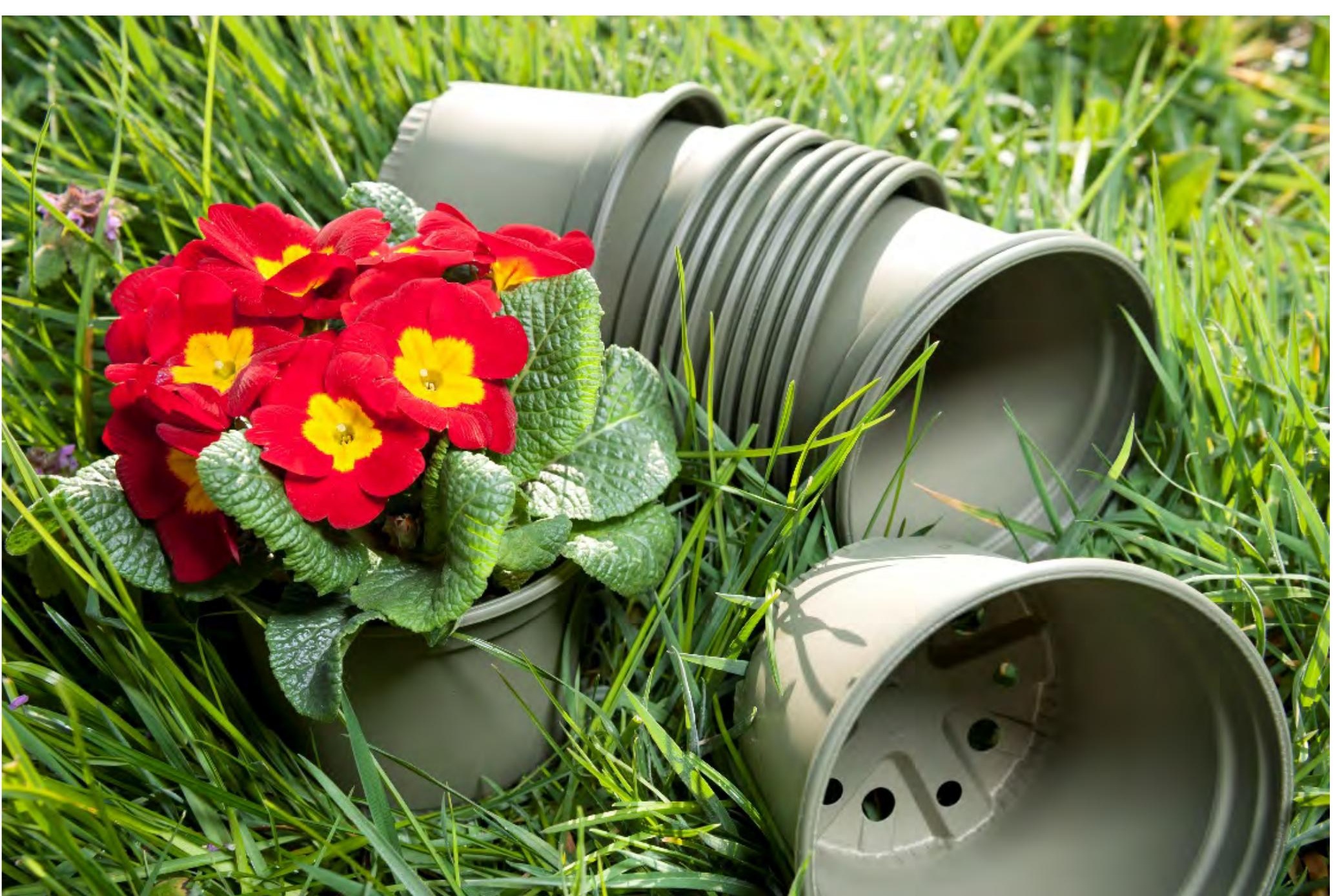





\section{Biobased plastics 2020}

Karin Molenveld and Harriëtte Bos, Wageningen Food \& Biobased Research

Cover illustration: D-grade plant pots (Desch Plantpak) 


\section{Published in the series "Green Resources"}

- Textiles for circular fashion: Part 1, Fibre resources and recycling options, Paulien Harmsen, Harriëtte Bos (2020)

- Catalogus biobased bouwmaterialen 2019; Het groene en circulaire bouwen, Jan van Dam, Martien van den Oever (2019)

- Biobased plastics 2019, Karin Molenveld and Harriëtte Bos (2019)

- Lignine, groene grondstof voor chemicaliën en materialen, Jan van Dam, Paulien Harmsen, Harriëtte Bos, Richard Gosselink (2017)

- Artificial Photosynthesis; For the conversion of sunlight to fuel, Robin Purchase, Huib de Vriend and Huub de Groot, editors: Paulien Harmsen and Harriëtte Bos (2015)

- Biobased Packaging Catalogue, Karin Molenveld and Martien van den Oever (2014)

- Duurzaamheid van biobased producten uit plantaardige olie, energiegebruik en broeikasgasemissie. Harriëtte Bos, Sjaak Conijn, Wim Corré, Koen Meesters, Martin Patel (2013)

- Green building blocks for biobased plastics; Biobased processes and market development, Paulien Harmsen, Martijn Hackmann (2012)

- Catalogus biobased bouwmaterialen; Het groene bouwen, Jan van Dam, Martien van den Oever (2012)

- Biocomposieten 2012; Natuurlijke vezels en bioharsen in technische toepassingen, Martien van den Oever, Karin Molenveld, Harriëtte Bos (editor) (2012)

- Biobased Plastics 2012, Christiaan Bolck, Jan Ravenstijn, Karin Molenveld, Paulien Harmsen (editor) (2011)

- Microalgae; the green gold of the future? Large-scale sustainable cultivation of microalgae for the production van bulk commodities, Hans Wolkers, Maria Barbosa, Dorinde Kleinegris, Rouke Bosma, Rene Wijffels, Paulien Harmsen (editor) (2011)

- Duurzaamheid van biobased producten; Energiegebruik en broeikasgasemissie van producten met suikers als grondstof, Harriëtte Bos, Sjaak Conijn, Wim Corré, Koen Meesters, Martin Patel (2011)

- Bioraffinage; Naar een optimale verwaarding van biomassa, Bert Annevelink, Paulien Harmsen (2010)

These, and older editions, may de downloaded from www.groenegrondstoffen.nl 


\section{Preface}

This booklet "Bioplastics 2019", published in the Green Resources series, is a reprint of the Bioplastics 2012, that was a joint initiative of the DPI Value Centre and the Biobased Performance Materials Programme. This new edition provides an overview of the current state of affairs in the bio-based plastics market. This edition was created at the request of the Ministry of Economic Affairs and Climate Policy and the TKI-BBE (Top Consortium for Knowledge and Innovation in the Biobased Economy).

This booklet shows what bioplastics are currently available on the market, and what developments may be expected. This includes thermoplastics and thermosetting materials. The booklet provides insight into the production, processing, characteristics and possible applications of the different types of bioplastics. Moreover, possible uses, waste management and technical, economic and environmental issues are discussed.

Biobased plastics 2019 was written with everyone who is interested in bioplastics in mind, whether it be a societal or business interest, or simple curiosity about the current state of affairs. We aim to show entrepreneurs the many possibilities bioplastics have to offer, provide students with information on this novel research domain and support civil servants in their policy-making.

Karin Molenveld and Harriëtte Bos 



\section{Content}

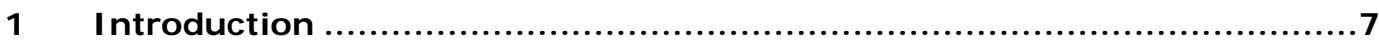

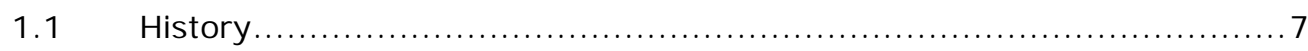

1.2 Bioplastics in the "new circular economy" ...................................

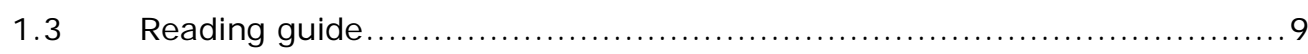

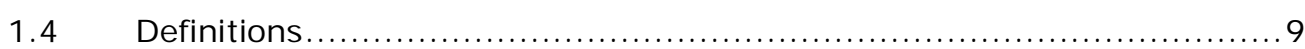

2 Thermoplastics based on bio-based monomers .................................13

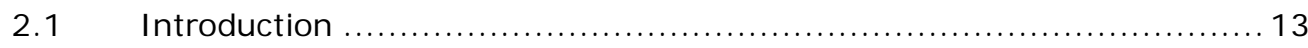

$2.2 \quad$ Bio-based polyesters ........................................................... 13

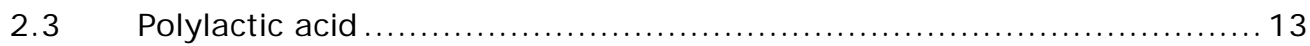

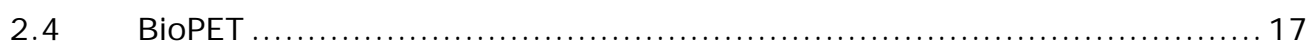

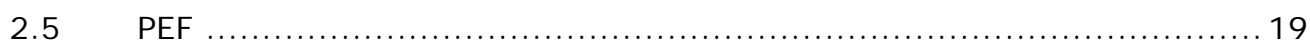

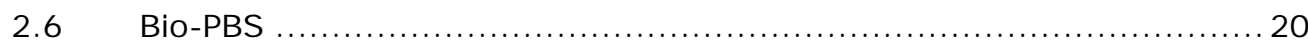

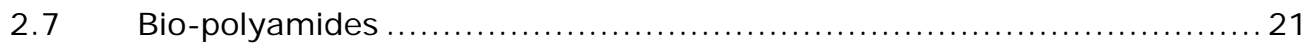

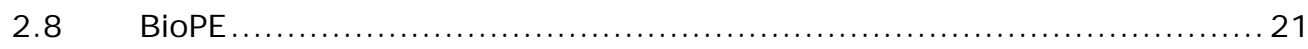

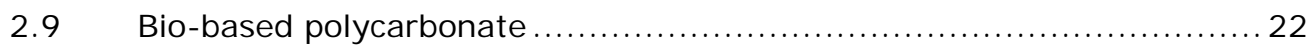

2.10 Bio-based thermoplastic elastomers ........................................ 22

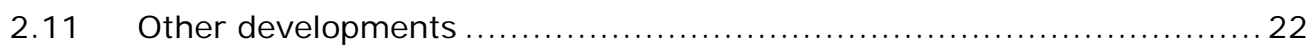

3 Thermoset materials based on bio-based monomers ...........................25

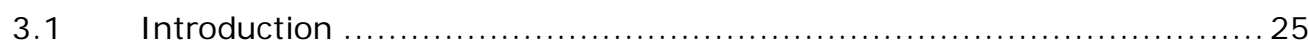

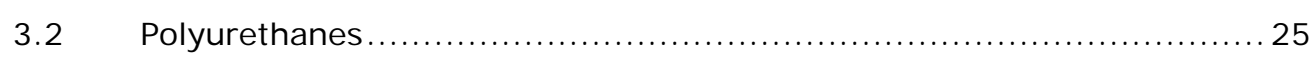

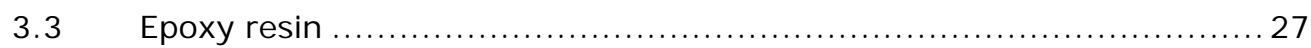

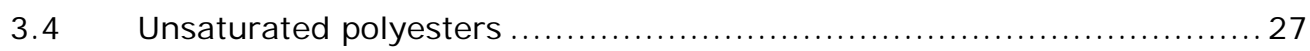

3.5 Alternative reactive systems based on fatty acids ........................ 28

3.6 Furan resins ...................................................................... 28

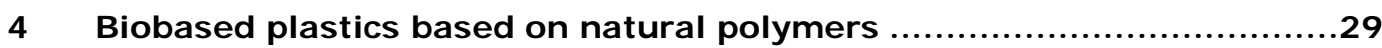

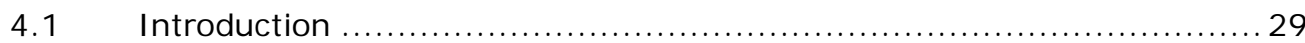

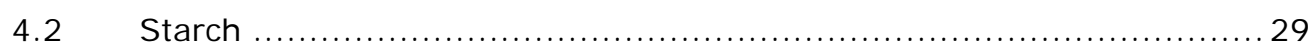

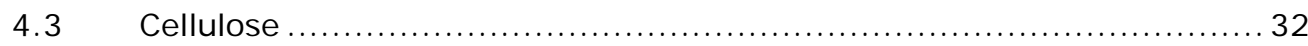

4.4 Bio-based polymers from micro-organisms ................................ 35

$4.5 \quad$ Natural rubber .................................................................... 38

$5 \quad$ Processing bio-based plastics into products .........................................

$5.1 \quad$ Introduction ................................................................. 41

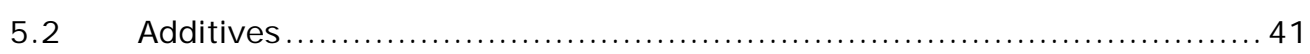

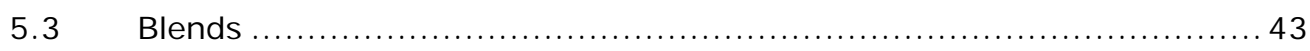

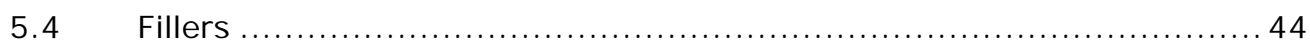

$5.5 \quad$ Product development ........................................................... 44 


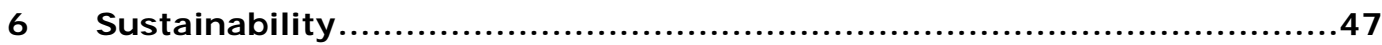

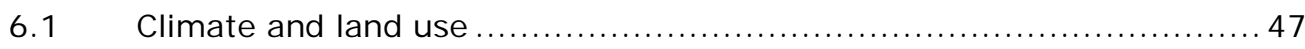

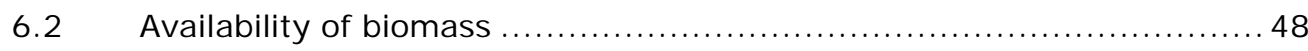

6.3 Waste management and circularity ....................................... 49

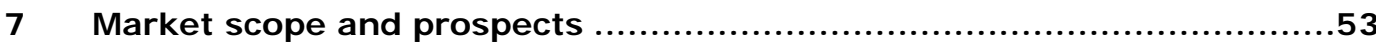

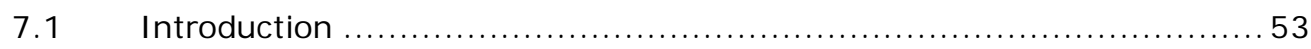

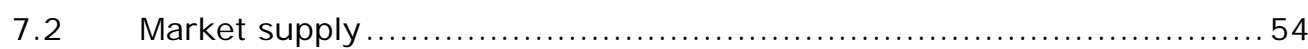

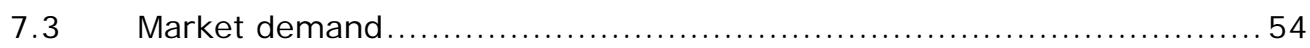

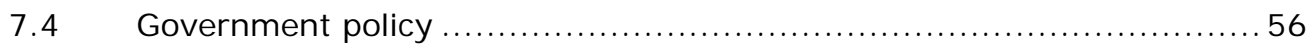

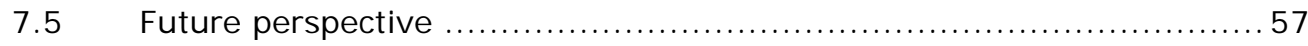

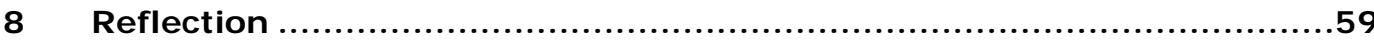

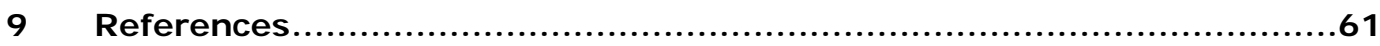

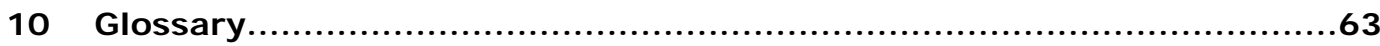

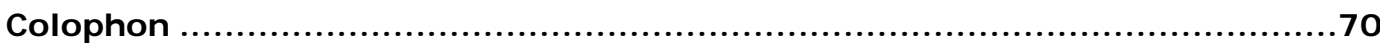




\section{Introduction}

\subsection{History}

For as long as we can remember, natural polymers such as wood and cotton have been used in food, clothing and construction materials. The industrial revolution led to the rise of the first (human-made) biobased plastics and synthetic materials. Celluloid, a material based on cellulose, was first discovered in 1860 and was already being used as a replacement material for ivory around the turn of the century. Not long thereafter, rayon and cellophane were introduced as materials for clothing and packaging.

In the first half of the twentieth century, a different type of polymers, produced from petrochemical raw materials such as petroleum, became dominant. Materials made from these polymers have shown spectacular growth over the past century and are known as synthetic plastics.

Times have changed, and presently, bio-based plastics are once again in the spotlight due to climate concerns and the declining oil supplies, but also as a result of technological developments in, for example, industrial biotechnology and increasing concerns over the environment and plastic waste. The usage of bio-based polymers was being rediscovered, for example using starch as a thermoplastic material, and polylactic acid as a promising new plastic for bulk-purposes like packaging. Moreover, innovative biotechnological production technologies are developed that allow micro-organisms to produce polymers and the building blocks used in polymers.

Bio-based plastics are defined as macro-molecules made or processed by man, extracted from biological resources for thermoplastic and thermosetting applications, both for bulk and technical purposes. This type of materials is a sub-group of biobased polymer materials, that includes materials such as wood, paper and cardboard, certain types of paint and cotton.

Since the start of this century, remarkable progress has been made in the field of production of bio-based plastics. New types of polymers and new technologies lead to a wider range of possible uses. Even multinationals of petrochemical origin have jumped on the bandwagon, resulting in new bio-based plastics being introduced to the market even faster.

The main raw materials currently being used in the production of bio-based plastics are carbohydrates, mainly starch, but also sugars and cellulose. In addition, natural oils such as palm oil, castor oil, soy oil and linseed oil are used. Other ingredients from plants can also be used, for example, proteins and lignin, as well as ingredients from animals: the chitin from crustaceans. The option of using marine biomass is currently being 
studied with keen interest. Micro and macroalgae (seaweeds) are viewed as a new potential source of carbohydrates, natural oils and proteins.

\subsection{Bioplastics in the "new circular economy"}

Plastics are generally associated with a myriad of environmental issues ranging from an increase in greenhouse gasses to litter, and from microplastics to "plastic soup". The Ellen McArthur Foundation described what "the new plastic economy" should look like in a model. This model is widely accepted, and both governments and the trade and industry sector base their policies on it. The three key elements in "the new plastic economy" are:

1. All plastics must be used circularly (repurposed) as much as possible in applications of equal value

2. Leakage of plastics into the environment is to be avoided

3. The production of virgin plastics is to be renewably sourced

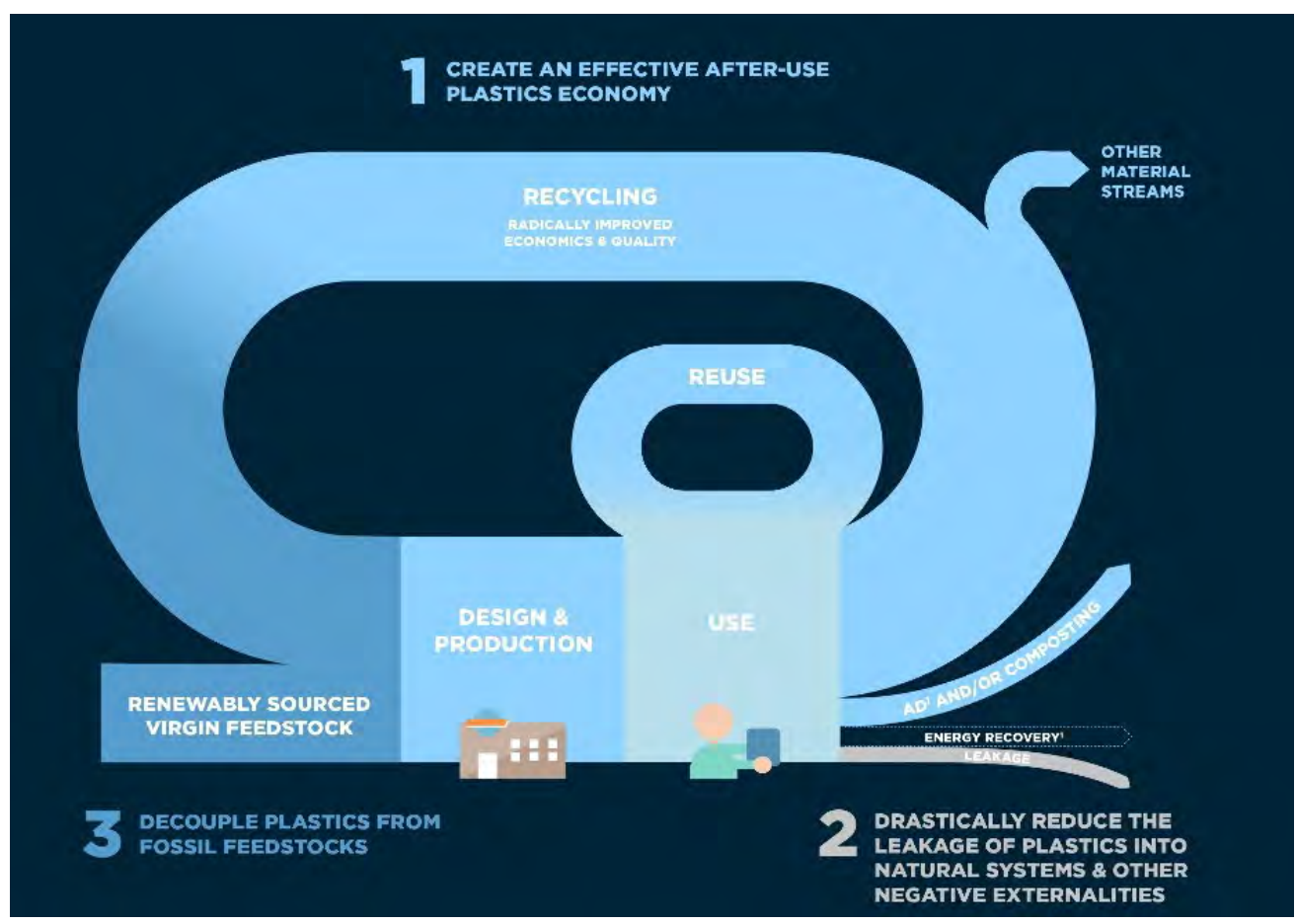

The "new plastic economy" (Ellen Mac Arthur Foundation) ${ }^{1}$

\footnotetext{
${ }^{1}$ www.ellenmacarthurfoundation.org/our-work/activities/new-plastics-economy
} 
Bio-based plastics are an important element in this model due to the decoupling of fossil feedstock. The recyclability of bio-based plastics is a prerequisite. In addition, biodegradable plastics may be used in products that are unavoidably released into the environment.

\subsection{Reading guide}

The next three chapters discuss the leading bio-based plastics that are commercially available. Chapters 2 and 3 are dedicated to bio-based plastics that are based on biobased monomers, both thermoplastics and thermosetting materials. Chapter 4 deals with synthetic materials based on polymers created by micro-organisms. Where relevant, in each chapter, we will discuss technical aspects such as production, processing, uses and technological developments, but also other aspects such as price and availability. In chapter 5, we will expand on how these bioplastics can be turned into products with the help of additives, fillers and blending.

In chapter 6, the most important sustainability-related aspects regarding such issues as availability and production of biomass, effects on the climate, biorefinery, waste management, circularity and GMO are discussed. Chapter 7 deals with market demand and supply, the effects of government policy and future perspectives. The concluding chapter 8 discusses recent developments that will play an important part in the future development of bio-based plastics. Finally, an index and a list of terms and abbreviations are provided.

\subsection{Definitions}

The following frequently used terms are explained below to improve the readability of this booklet.

\section{Bioplastics}

A term that is used to describe both biodegradable plastics and renewable plastics, and, as such, may cause confusion. In the past, this term was used primarily for biodegradable plastics. At present, the focus in bioplastics lies mainly in its renewable aspect (bio-based); these plastics are not by definition biodegradable. To avoid confusion, it is, therefore, better to use the terms bio-based plastics and biodegradable plastics.

\section{Bio-based content}

This signifies the part or percentage of the product weight that is based on renewable resources. At first, only the amount of recently stored carbon in a product was taken into consideration when determining the bio-based content. Various standards are available for this so-called C14-method (ASTM D6866, ISO 16620-4 and 16640) that 


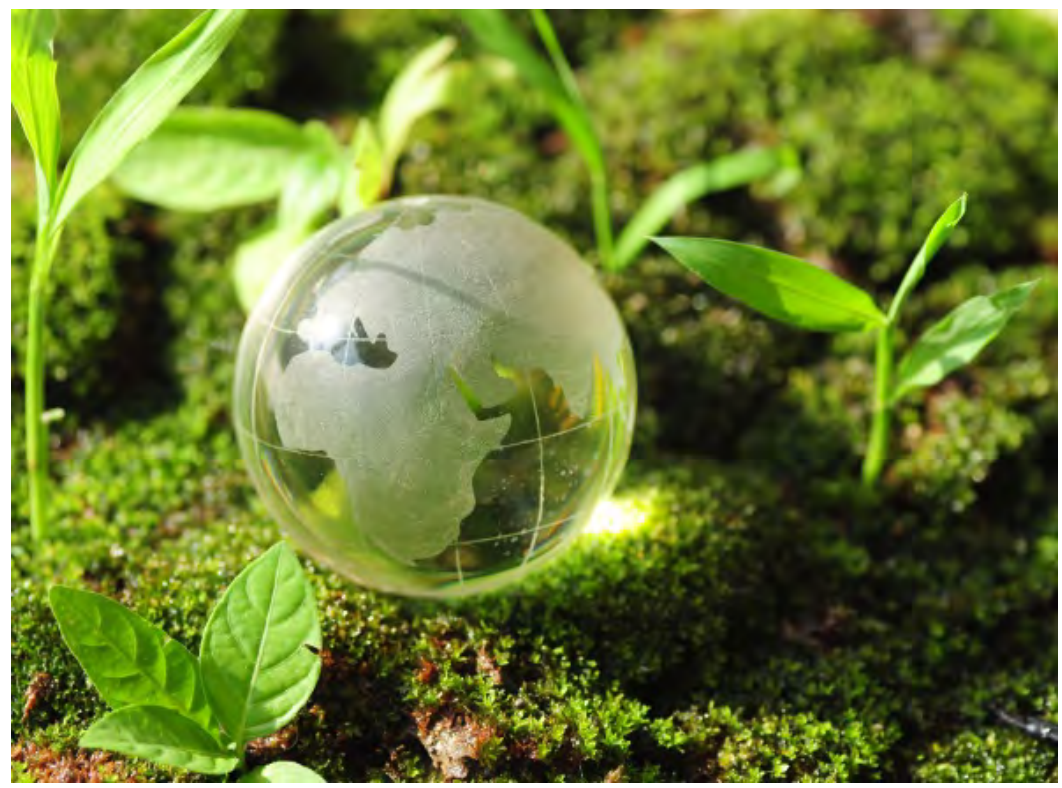

Bioplastics usually have a positive environmental profile

serves to determine the "bio-based carbon content". Since 2016 a (European) EN standard (EN 16785-1) is available, that includes other elements such as oxygen and nitrogen in addition to carbon, in determining the bio-based content.

Certified renewable or bio-based

Several large petrochemical producers market plastics as "certified bio-based". These producers add a percentage of biomass as a feedstock to their naphtha crackers. Based on the amount of biomass, a mass-balance approach is used to award an equal percentage of the produced plastics with the certificate "renewable". Because the biobased content of these plastics cannot be measured through the aforementioned methods, they may not be termed "biobased", but rather "certified bio-based" or "certified renewable".

Biodegradable or bio-decomposable

These are plastics that can be degraded into carbon dioxide $\left(\mathrm{CO}_{2}\right)$ and/or methane by micro-organisms (such as bacteria and fungi). Whether a substance is biodegradable, depends on its chemical structure. Certain polyesters may be degraded by microorganisms through the presence of ester linkages. Polymers such as polyethylene (PE) and polypropylene (PP), contain only carbon and hydrogen, and can therefore not be 
degraded down by bacteria or fungi. In addition to the chemical structures, environmental conditions also influence the degree and speed of biological degradation. Such environmental factors include temperature, availability of oxygen and water, and the type and number of micro-organisms (fungi and bacteria).

\section{Compostable plastics}

These are plastic packaging materials that meet the EN13432 standard, an international standard for compostable plastics, and that can biodegraded sufficiently fast in industrial composting installations under controlled circumstances. The EN standard defines how fast and to what degree a biodegradable plastic must degrade under commercial composting conditions.

Whether a plastic is compostable depends, among other things, on product geometry and possible additives. Thus, a product made of a biodegradable polymer such as PLA may fail to decompose if the product is too thick ( $>2 \mathrm{~mm}$ for PLA layers) and cannot be accepted due to ecotoxicity issues if the product contains heavy metals from, for example, colouring agents. In recent years, the industrial composting processes have been altered to increase the throughput of organic waste. This has led to uncertainty on whether products meeting the EN13432 standard still degrade sufficiently fast in the new composting plants. However, recent research has shown that also under the presently applied practical conditions certified products biodegrade sufficiently fast. ${ }^{2}$

\section{EN13432}

According to this standard, plastic packaging may only be called compostable if it is proven that:

- The material and its relevant components are naturally biodegradable

- Disintegration of the material takes place within a composting process for organic waste

- The product does not negatively impact the composting process

- The product does not negatively impact the quality of the compost

Oxo-degradable

Oxo-degradable plastics are materials to which additives have been added to allow them to degrade under the influence of oxygen (in the atmosphere). To date, there are no oxo-degradable products on the market that meet the EN13432 standard. There are

\footnotetext{
2 The fate of (compostable) plastic products in a full scale industrial organic waste treatment facility. Maarten van der Zee, Karin Molenveld, https://edepot.wur.nl/514397.
} 
concerns that oxo-degradable plastics may contribute to pollution in the form of microplastics. The EU released a report at the start of 2018, in which it petitions for measures against oxo-degradable plastics. As a result these materials will be banned in the EU by July $2021 .^{3}$

\section{Classification}

Based on the aforementioned definitions, plastics can be categorised according to the chart below, that includes several examples:

\begin{tabular}{|c|c|c|c|}
\hline & Petrochemical & partly biobased & Biobased \\
\hline Not biodegradable & PE & bioPET & Nylon 11 \\
\hline Biodegadable & PCL & Starch blends & PLA \\
\hline
\end{tabular}

\section{Petrochemical: $\quad$ Crude oil-based}

Partly biobased: $\quad$ Plastics based on both crude oil and renewable resources

Bio-based: $\quad$ Based entirely on renewable resources

Please be aware that plastics may be partly bio-based but not partly biodegradable, as this may lead to the occurrence of microplastics.

\footnotetext{
3 The European Union has recently banned the use of oxo-degradable plastics because of a lack of consistent evidence about speed of breakdown in the environment, and fears that false claims around this are misleading consumers. The directive 2019/9044 came into force on 3 July 2019 and has to be transposed by the Member States by 3 J uly 2021.
} 


\section{Thermoplastics based on bio-based monomers}

\subsection{I ntroduction}

Thermoplastics are materials in which the polymer chains are not chemically crosslinked, and that become soft or melt under heat. There are two possible developments that we can identify with regard to bio-based thermoplastics:

Production of bio-based polymers that are chemically identical to petrochemical polymers

Examples include bio-polyethylene (bioPE), various polyamides en polyesters. Because these biobased polymers are identical to their petrochemical counterparts, the materials have identical characteristics-the use of bioPE results in products that are equal to products made from petrochemically sourced PE.

Production of completely new monomers and polymers based on bio-based resources Examples of polymers that cannot easily be made from petrochemical ingredients are polylactic acid, furan-based polyesters, polyesters based on 1,3-propanediol and several polyamides such as nylon 11 . These polymers have unique characteristics that require further research into processing, use of additives and product development.

\subsection{Bio-based polyesters}

\subsubsection{Introduction}

Polyesters are polymers in which the monomers are linked through esters bonds. They are produced through polycondensation of a di-acid with a di-alcohol, through polycondensation of a hydroxy acid or through a ring-opening polymerisation of a lactone. These bio-based building blocks can be produced by micro-organisms (fermentation processes) or through chemical processes. Because bio-based resources are naturally richer in oxygen than petrochemical resources, the production of (building blocks for) bio-based polyesters is often more efficient and cost-effective than the manufacuture of polyolefins from this feedstock.

\subsection{Polylactic acid}

Polylactic acid (PLA) is currently the most important bio-based polyester and one of the most notable examples of a 100 per cent bio-based polymer. PLA has excellent properties; it is rigid, transparent, glossy and compostable in industrial composting plants. It was originally an expensive polymer ( $>€ 50 / \mathrm{kg}$ ) that was primarily used in the biomedical industry (implants and sutures). Through the development of efficient bulk polymerisation processes, it is currently one of the most affordable bio-based 
plastics at $€ 2-3$ per kilogramme, depending on the specific grade and producer. This relatively low price that has remained unchanged through recent years has made a transition towards bio-based polymers possible. PLA is readily available, with a large production facility in the United States capable of producing 150 kilotonnes annually, and another large facility in Thailand with an annual capacity of 75 kilotonnes. Besides, there are several smaller production facilities in China and Europe and further expansion of production capacities has been announced.

\subsubsection{Production of PLA}

Until recently, PLA was produced primarily in the United States from corn starch. In the USA, genetically modified corn is cultivated, and hence, also used as a resource for PLA. In some European countries, however, the use of such crops is contentious. Thus, PLA made from non-modified corn starch is also available on the European market.

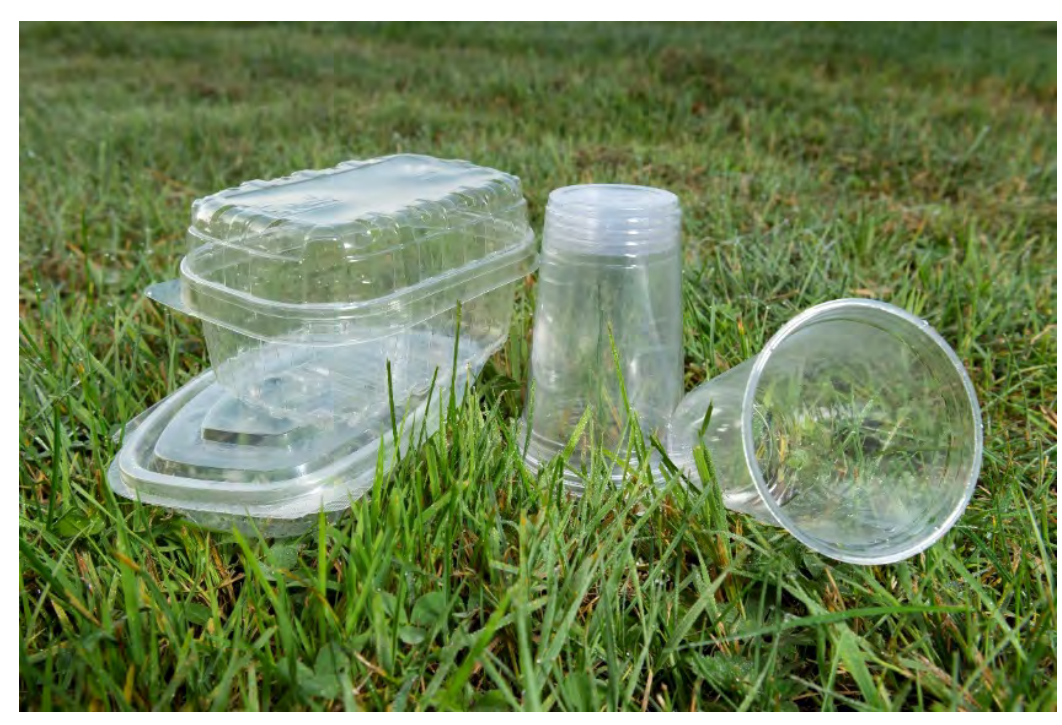

Thermo-formed PLA products (NatureWorks)

Genetically modified corn is not needed for the production of PLA. This plastic can be made from any crop containing starch (potatoes, tapioca) or sugar (sugar beet, sugar cane). The local availability of resources generally determines what is used for the production of PLA. In Thailand, for example, PLA is made from sugar cane.

Starch or sugar is fermented to produce lactic acid. This is a very efficient process, in which each sugar molecule produces two lactic acid molecules, without direct formation of side-products. It is not possible to produce PLA directly from lactic acid through a bulk 
polycondensation process, as this yields a polymer with a low molecule mass and inferior properties. PLA of good quality is commonly produced from lactides (cyclical dimers of lactic acid) through a very efficient ring-opening polymerisation.

Lactic acid is a chiral (optically active) compound existing in two forms (L- and D-lactic acid). Polymerisation allows for the production of different polymers: pure L- or Dpolylactic acid, or a copolymer of both L- and D- lactic acid. The properties of PLA depend on the stereo-chemical purity, i.e. the $L$ and $D$ content. Pure poly L-lactic acid (PLLA) or poly D-lactic acid (PDLA) has a crystallinity of approximately $37 \%$, a glass transition temperature $\left(\mathrm{T}_{\mathrm{g}}\right)$ of $60^{\circ} \mathrm{C}$ and a melting point of $175^{\circ} \mathrm{C}$. Most commercially available PLA grades consist of 85 to $99 \%$ L-lactic acid, and 15 to $1 \%$ D-lactic acid. Increasing the amount of $\mathrm{D}$-isomer results in a material that is less crystalline, and crystalises less rapidly, and has a lower melting temperature. PLA with a 10\% D-content or more is fully amorphous.

\subsubsection{Processing PLA}

PLA may be processed through the same methods as commonly applied to thermoplastics, including fibre spinning, extrusion and compounding, injection moulding and thermoforming. Processing temperatures range from $180^{\circ} \mathrm{C}$ to $220^{\circ} \mathrm{C}$ depending on the type of PLA and processing method.

Like all polyesters, PLA must be dried prior to processing (water content $<250 \mathrm{ppm}$ ). The melt strength of PLA is relatively low, which makes film blowing and extrusion foaming impossible without using additives to improve the melt strength, or mixing the PLA with other polymers. However, the production of expandable bead foam (similar to EPS) and biaxially drawn films is possible. PLA is also a frequently used material in 3Dprinting.

The crystallisation rate of most of the commercially available PLAs is low, which is why almost all PLA products are amorphous. The maximum temperature under which an amorphous PLA product is usable (heat deflection temperature, HDT) lies around $55^{\circ} \mathrm{C}$. This makes commercially available transparent thermoformed PLA cups suitable only for cold beverages. This low usage temperature causes issues in warmer climates. But problems can also occur in colder climates if the PLA product is stored in a warm location such as material in a sealed container or behind glass or in direct sunlight.

If specific PLA grades are used under the correct processing circumstances, products with high crystallinity can be made. PLA coffee cups to replace the standard polystyrene cups form an excellent example.

\subsubsection{PLA properties}

The relatively low cost, commercial availability of various grades (for many processes and uses), transparency, high level of gloss and rigidity are among the many advantages 
of PLA. In many applications, PLA can easily replace polystyrene or PET (Poly-Ethylene Terephthalate). The aforementioned low HDT and melt strength and sensitivity to hydrolysis (when insufficiently dried) during processing are disadvantages of PLA, as well as the fact that the material itself is brittle and has a low tear strength.

Over the past years, many additives and masterbatches have been developed that can be added to improve the properties of PLA. For example, additives to improve impact strength (impact modifiers) and chain extenders that increase the melt strength. Some of these additives may negatively impact transparency or compostability. Additionally, properties may be enhanced through blending with other (bio-based) polymers. The PLA blend with PBAT (polybutylene adipate terephthalate) is the best known. This petrochemical biodegradable polyester makes PLA tougher and more widely usable. Further information on improving material properties of bio-based plastics is provided in chapter 5.

PLA can be composted in industrial composting installations and is not suited for home composting. It is essential that the temperature during the composting process is sufficiently high, at approximately $60^{\circ} \mathrm{C}$. PLA can be fermented for methane production under thermophilic anaerobe conditions. An alternative end-of-life scenario is using hydrolysis to transform the PLA into a lactic acid monomer, followed by renewed production of lactides and PLA. This process is known as chemical recycling. PLA can also be mechanically recycled.

\subsubsection{Uses of PLA}

PLA as a bio-based and compostable plastic was initially used primarily in packaging, disposables and fibres (textile and non-woven). Examples of PLA-based packaging and disposables available on the market are transparent films, disposable cutlery, thermoformed products such as cups, flowerpots and meat dishes, as well as foamed (transportation) packaging.

Fibre applications of PLA are found in teabags, diapers and tissues, but also in bedsheets, carpets and curtains. PLA is also used as a paper coating (coffee cups) and in adhesives, including hotmelts. There is an increasing demand for PLA in sustainable applications such as electronics, car parts and building and construction products. Heat resistant PLA (PLA with a high HDT) helps make these novel uses possible. To this end, PLA can be filled with glass fibres. Examples of applications in building and construction are PLA foam (isolation material), wall cladding, flooring and profiles that protect walls and doors.

\subsubsection{Developments regarding PLA}

The most significant development regarding PLA is the fabrication of products with a high temperature resistance. This is achieved through blending with bio-based or 


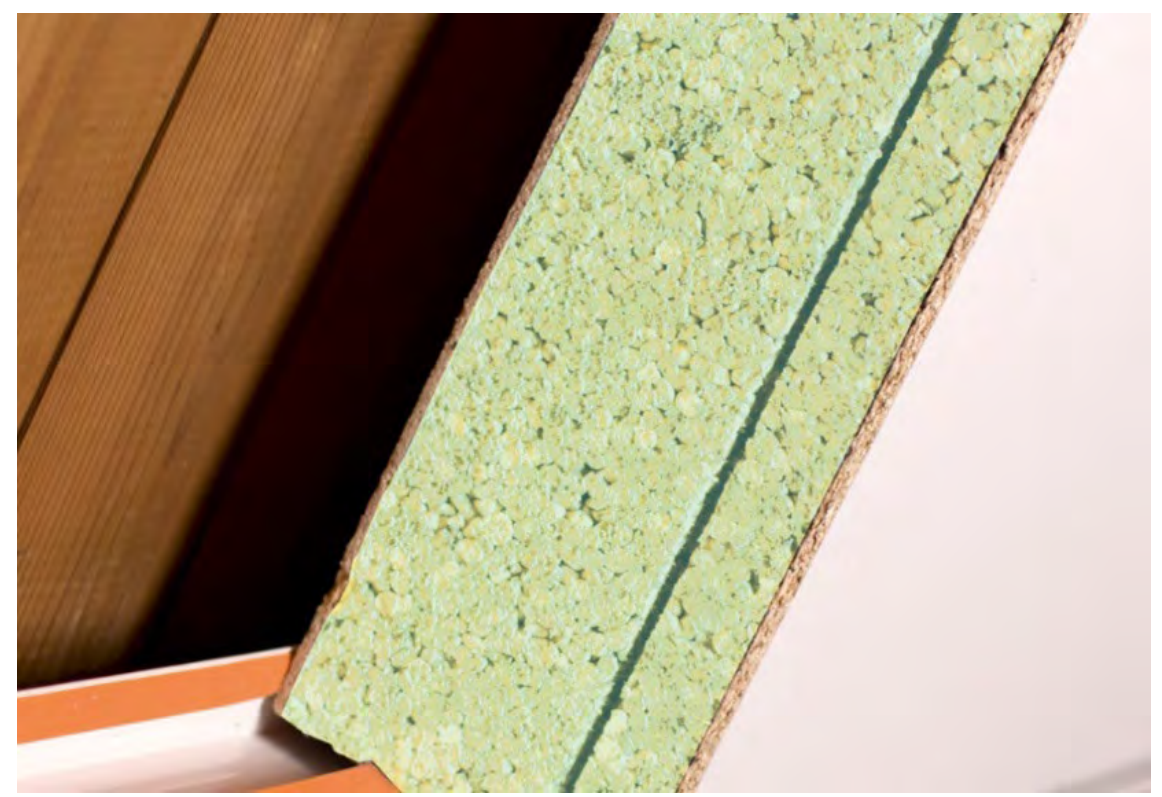

Biofoam isolation material (PLA-based polystyrene, Bewi-Synbra)

petrochemical plastics, or by allowing the PLA to crystalise more rapidly. Nucleating agents such as talcum, EBS (ethylene bis-stearamide) and PDLA (poly D-lactic acid) have been proven to substantially increase the rate of crystallisation. The use of PDLA to form sc-PLA (stereocomplex PLA) is the most promising and effective in this regard. Sc-PLA is formed by the co-crystallisation of PLLA and PDLA and has a melting point of $230{ }^{\circ} \mathrm{C}$. In general, using nucleating agents is not sufficient to achieve a heat resistant product. Processing conditions must also be adjusted, for example, injection moulding and thermoforming using a heated (approx $100{ }^{\circ} \mathrm{C}$ ) mould.

The use of blends with other bio-based polymers for optimisation of properties such as toughness and tear-resistance is another trend. There are also developments in the area of resource usage; for example, the use of designated waste streams to produce lactic acid such as whey or the production of lactic acid from methane or carbon dioxide.

\subsection{BioPET}

PET (Polyethylene terephthalate) is among the 5 most sold plastics in the world. Twothirds of the global production volume is applied towards the production of fibres and textiles (such as fleece sweaters), and one third is used in packaging, of which the PET soda bottles are the best known. In 2009, Coca-Cola launched the 'plant bottle', which is made from bioPET. BioPET is an example of a partial bio-based polyester and has 


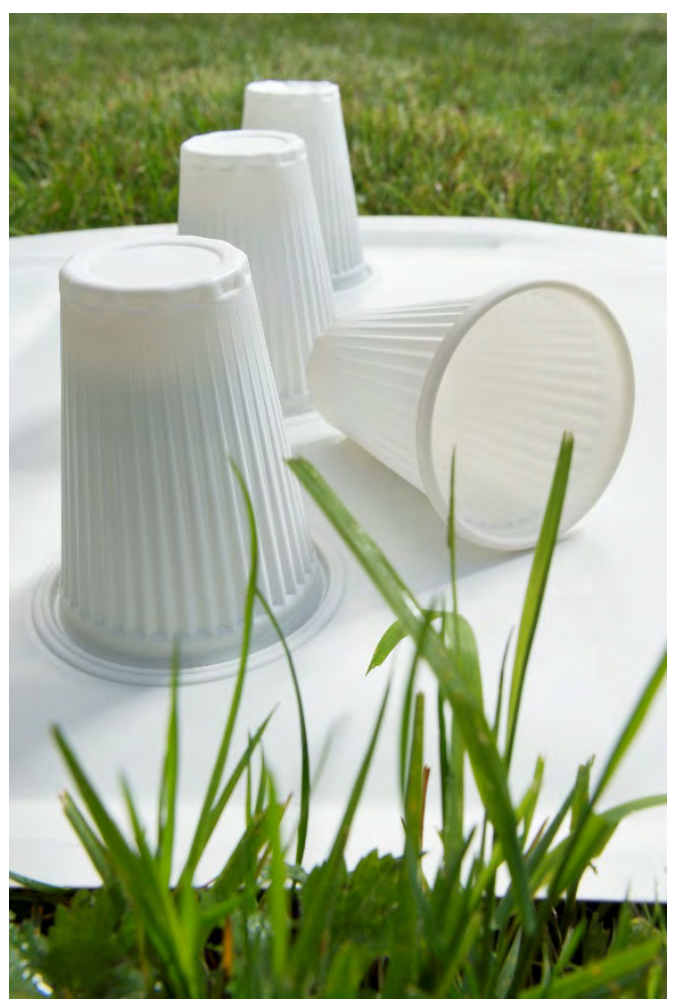

PLA-based coffee cups (Corbion)

exactly the same chemical structure as traditional PET. BioPET can easily be applied in products and processed through existing recycling streams without issues. Based on the production volume, bioPET is currently one of the most important bio-based plastic.

PET is made by polymerisation of ethylene glycol and terephthalic acid. The bioPET currently available on the market is produced through the polymerisation of ethylene glycol obtained from biological resources, with terephthalic acid based on crude oil. The number of carbon atoms indicates that bioPET is $20 \%$ bio-based. Nonetheless, this bioPET is an environmentally friendly choice in terms of $\mathrm{CO}_{2}$ emissions and depletion of energy sources.

The development of $100 \%$ bioPET is a next step that requires the second ingredient, terephthalic acid, to be produced from bio-based resources. Although complex, it is technically possible to produce bio-based terephthalic acid. The routes that are under development are varied and range from strictly chemical routes to a combination of fermentation and chemical processes. In all cases, multiple steps are required. Sugars and lignin are potential raw materials for the synthesis of bio-based terephthalic acid. 
Due to the complexity of producing bio-based terephthalic acid, research focuses on the development of more economical production processes but also on scaling up existing production processes.

\subsubsection{BioPET-related developments}

Instead of bio-ethylene glycol, 1,3 propanediol (PDO) is polymerised in combination with terephthalic acid to produce polytrimethylene terephthalic acid (PTT). PDO is produced through fermentation of starch. PTT, which is a lot like PET, was commercialised in 2000. PTT is currently applied primarily in textiles and carpets. Its advantages are a higher degree of bio-based material, but also specific characteristics such as improved stretch and elasticity.

Another interesting variation on PET is polyethylene isosorbide terephthalate (PEIT). In PEIT, part of the ethylene glycol is replaced with isosorbide. Isosorbide is produced through dehydrating sorbitol, a sweetener made from hydrogenating glucose. Adding isosorbide increases the PET's $T_{g}$, with the material becoming less crystalline due to the introduction of irregularities in the polymer chain.

\subsection{PEF}

In addition to the production of bio-terephthalic acid, there are also efforts to replace terephthalic acid with 2,5-furane dicarboxylic acid (FDCA) for the production of PEF (polythene furan dicarboxylic acid). FDCA may be synthesised from sugars through chemical processes and fermentation. The production of FDCA from sugars appears to be more cost-effective than the production of bio-terephthalic acid.

Because FDCA has a molecular structure that differs from that of terephthalic acid, PEF has different properties than PET. The reported barrier properties of PEF for $\mathrm{CO}_{2}$, water and oxygen are significantly better than those of PET.

FDCA and PEF are not yet produced on a large scale. The construction of the first FDCA plant in Antwerp (Belgium) by Synvia (Avantium and BASF joint venture) with a 50 kilotonne annual capacity was announced but has also been cancelled. The revised plan includes a "cash-flow positive flagship" plant which is to have a 5,000 t/y capacity for both FDCA and PEF to be built in northwestern continental Europe and expected to begin operations in 2023. At least two other companies or consortia are working on commercialising PEF and FDCA related materials. Corbion, for example, has developed a fermentation process for the production of FDCA and ADM and DuPont are collaborating on the production of PTF (polytrimethylene furanoate), a combination of FDCA and biobased 1,3 propanediol. 


\subsection{Bio-PBS}

PBS (polybutylene succinate) is a polyester that is produced through co-polymerisation of succinic acid and 1,4-butanediol. Succinic acid and 1,4-butanediol are currently mainly made from petrochemical raw materials and are so-called C4-chemicals. C4-chemicals are relatively costly, and succinic acid may be produced cheaper through biological processes such as the fermentation of glucose. Since $\mathrm{CO}_{2}$ is inserted during the fermentation reaction, succinic acid is an environmentally sound bio-based material. Several large companies and consortia are involved in the development and scale-up of bio-based succinic acid production. Succinic acid can also de used to produce 1,4butanediol, which allows for the production of $100 \%$ bio-based PBS. The successful implementation and scale-up of new technologies could lead to a significant drop in prices of PBS, and 50\% bio-based PBS is now commercially available.

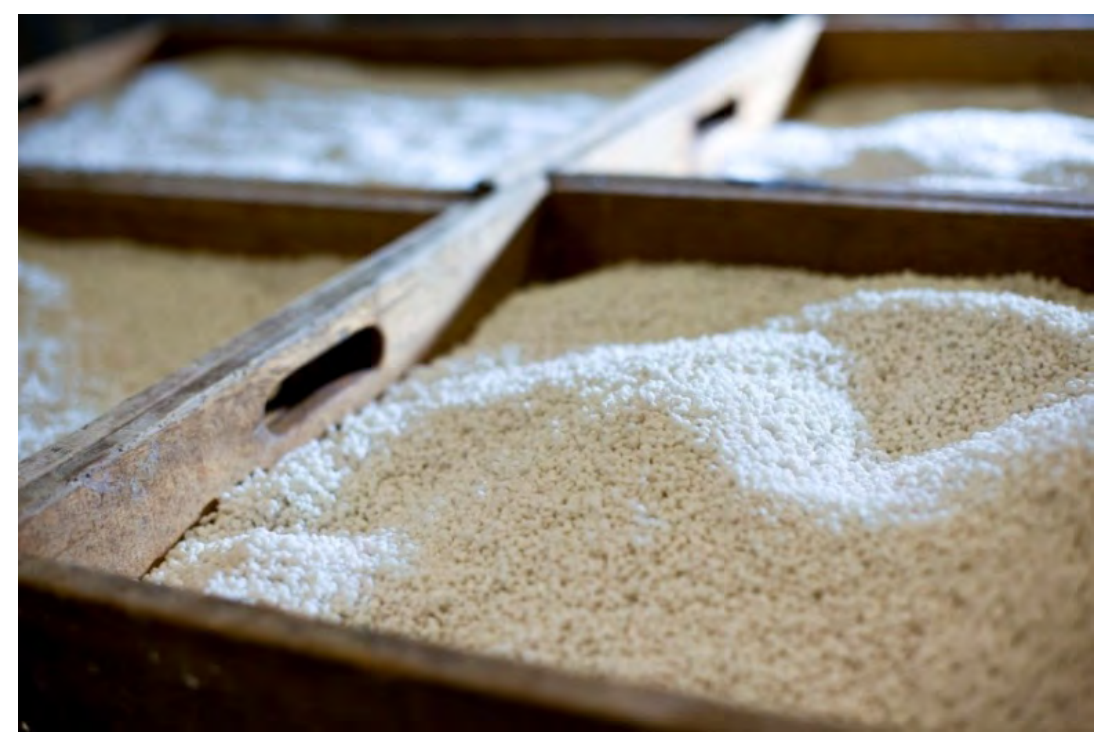

Drying bio-plastic granulate

PBS is biodegradable and compostable. The mechanical properties of PBS are similar to polypropylene (PP) and high-density polyethylene (HDPE). Compared to many other biopolymers, PBS has a higher heat deflection temperature (HDT) and is much tougher. It also crystalises rapidly, which makes it easy to process using injection moulding. The properties of PBS-polymers can be altered by the introduction of other monomers such as lactic acid, terephthalic acid and adipic acid. PBSA (with adipic acid), for example, is 
much more flexible than PBS and biodegrades much more easily in the natural environment.

PBS polymers are excellent components for bio-based blends with other polymers such as PLA, polyhydroxyalkanoates (PHA) or thermoplastic starch (TPS). The current global production of PBS amounts to some 40 kilotonnes per annum, and there are ambitious growth plans.

\subsection{Bio-polyamides}

Polyamides, better known by their generic name nylons, are an important type of highperformance plastics (engineering plastics). They are produced by polycondensation of a di-acid and a diamine, or through the ring-opening polymerisation of a lactam (cyclic amide compound). Polyamides are named after the number of carbon atoms in each of the monomers. The best-known polyamide is PA 6,6, where the first 6 stands for the six carbon atoms in the diamine (1,6-hexane diamine) and the second 6 stands for the 6 carbon atoms in the dicarboxylic acid (adipic acid) PA 6 is produced through ring-opening polymerisation of caprolactam, which also contains 6 carbon atoms.

Polyamides can be made bio-based through the use of monomers (diacids, diamine, lactam) from renewable sources. A well-known example of a bio-based polyamide is PA 11. The raw materials for this polyamide are made from castor oil also known as ricinus oil (extracted from the tropical species Ricinus communis). PA 11 is a high-performance polymer material used in the automotive industry and in oil and gas mining. This material that is naturally bio-based has been commercially available for over 70 years.

Several major plastic producing companies in Europe, America and J apan are marketing partially bio-based polyamides. Examples include PA 11, PA 6,10, PA 4,10 and PA 10,10. Almost all the bio-based components for these bio-polyamides are produced from castor oil. The commercial success of these materials and the polyamides that are still under development is largely contingent on the cost of producing the bio-based monomers.

\subsection{BioPe}

Polyethylene (PE) is the world's most-used plastic and has a market share of almost $30 \%$ of all thermoplastics. Bio-based PE is produced in Brazil, in a plant that has a 200kilo tonne annual capacity.

BioPE has properties identical to petrochemical PE but is produced from ethylene from bioethanol instead of crude oil. Brazil is a major producer of bioethanol through the fermentation of cane sugar. Bioethylene can be produced cost-competitive in Brasil compared to ethylene made from crude oil, because of the advanced infrastructure for bioethanol production. Still, bioPE is sold at a price that is 20-30 per cent higher. Companies appear willing to pay this higher price purely because the product is biobased and more sustainable. Large packaging companies of A-grade brands in food and 
cosmetics have already introduced bioPE into their packaging materials. These materials range from films, vials and tubes to drinking cartons with a PE coating.

\subsection{Bio-based polycarbonate}

For some time now, (partially) bio-based polycarbonate is commercially available. The material is based on isosorbide (from sorbitol) and has a bio-based content of approximately 60 per cent. The material is not identical to fossil-based polycarbonate. One advantage of bio-based polycarbonate is its combination of rigidity and abrasion resistance with excellent optical properties and UV-stability. The material is used in the automotive industry (interior and exterior) and electronics (touch screens).

\subsection{Bio-based thermoplastic elastomers}

Thermoplastic elastomers (TPEs) are elastic at room temperature but may be processed as thermoplastics at higher temperatures. By applying bio-based elements, thermoplastic elastomers may be made (partially) bio-based. The bio-based content of commercially available bio-based TPEs ranges from 40 to over 90 per cent. In general, the softer TPEs have a lower bio-based content than the more rigid varieties. The materials are available from various producers and are used in, for example, the soles of shoes.

\subsection{Other developments}

There are large scale efforts within the industry to develop and scale-up other thermoplastic polymers from bio-based raw materials. Bio-based ethylene (from bioethanol) for example, can be the basis for a great number of materials. Recently biobased polypropylene (PP) was introduced into the market but plans for the production of bio-based polyvinylchloride (PVC) from bioethylene have been put on hold but may be re-initiated in the future.

From a technological perspective, each petrochemical monomer can be produced from biological raw materials. By simple substitution, the traditional petrochemical plastics industry could be replaced by a bio-based plastics industry. Nonetheless, substitution is not likely to be the only road to bio-based plastics, for several reasons.

To better compete with petrochemical plastics in terms of pricing, plastics that can be produced more easily and cheaper from biological raw materials are being developed. Examples include PLA based on lactic acid and PBS based on succinic acid. Similar but not identical monomers replace petrochemical monomers because these are cheaper to produce from biological raw materials, such as FDCA, in comparison to terephthalic acid. In a study on the sustainability of bio-based products, the conclusion was that it is more sustainable to produce plastics in a way that maintains the original structure of the raw 
materials as much as possible ${ }^{4}$. This means that it is more sustainable, and cheaper in the long run, to use sugars for the production of PLA than for the production of bioPE (due to a greater reduction in feedstock use, energy use and greenhouse gas emissions). The success and growth in 'certified' renewable plastics will depend on the cost of renewable raw materials that are suited for mixing in with naphtha crackers.

Finally, there is a category of plastics produced from monomers that are dangerous to humans, such as bisphenol-A in polycarbonates. There is reason to assume the use of this type of monomer will be restricted in the future, and plastics it contains may be used sparingly only. Identical compounds based on biological raw materials are therefore not under development.

\footnotetext{
${ }^{4}$ Sustainability of biobased products; Energy use and greenhouse gas emissions of products containing sugar as a raw material, Harriëtte Bos, Sjaak Conijn, Wim Corré, Koen Meesters and Martin Patel, 2011, in the 'Green resources' series.
} 


\section{Thermoset materials based on bio-based monomers}

\subsection{Introduction}

Thermosets are polymers of which the chains are chemically interconnected. By using monomers with more than 2 functional groups, there is the option of creating cross-links or links between the chains. Unsaturated compounds in the polymer chain may also serve to introduce cross-links. The properties of the material depend on the number of cross-links (cross-link density). After curing, thermosets no longer flow, and can thus no longer be processed into a different shape as thermoplastics can.

As in the development of thermoplastics from bio-based monomers, there are two possible strategies for the development of thermosetting materials:

Replacing petrochemical components with bio-based components

This approach has the advantage of allowing a higher bio-based content in materials without too many adjustments to the production and processing. A disadvantage is that there is no bio-based alternative for various reactive groups. Thus, this approach makes it difficult to develop a $100 \%$ bio-based system.

Production of new thermoset materials from bio-based raw materials

In this route, research is done on how (reactive) naturally occurring components or components that can be easily produced from biological raw materials, may be used as efficiently as possible. This route has the disadvantage that new resin systems and curing conditions must be introduced, which may require additional investments or alterations in equipment or infrastructure.

\subsection{Polyurethanes}

Polyurethanes are a group of thermosetting polymers with a broad spectrum in properties and application possibilities. Polyurethanes are created through polymerisation of polyols (compounds with two or more hydroxyl groups) with (di) isocyanates (compounds with two or more isocyanate groups). The properties of the polyurethanes depend on the structure of the polyols and isocyanates. Current uses vary from flexible and hard foams to coatings, adhesives, sealants and elastomers.

Developments in the area of bio-based polyurethanes are mostly focused on bio-based polyols. Several large international producers market bio-based polyols that can specifically be used in polyurethanes: 
- Polyols made from natural oils (castor oil or soy oil) for various polyurethane applications

- 1,3-propanediol (through fermentation of sugars) for the production of polyether polyols

- Succinic acid or adipic acid (through fermentation of sugars) for the production of polyester polyols

- Sugar polyols for the production of polyols for hard polyurethane foams

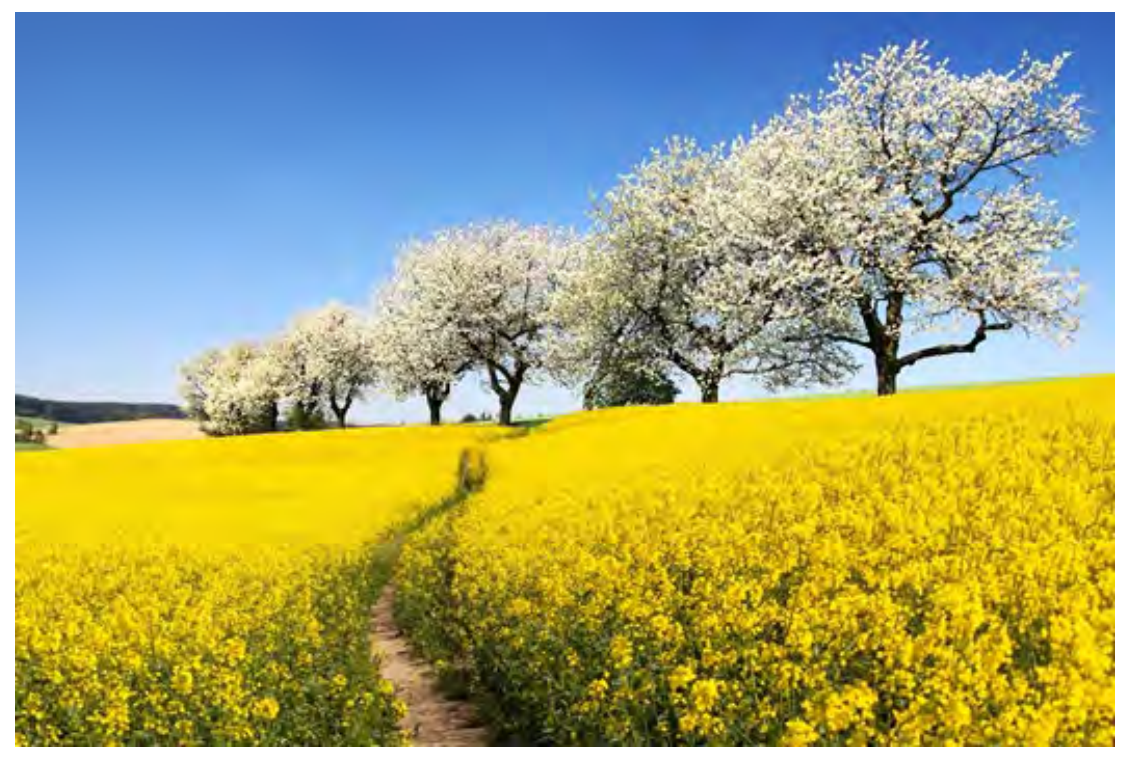

Rapeseed is the third largest vegetable oil in the world

Oils are esters of glycerine (or glycerol) and fatty acids. Castor oil or Ricinus oil is an important raw material in the production of bio-based polyols as it contains reactive hydroxyl groups. Ricinoleic fatty acid contains a double bond in the middle of its carbon chain, as well as a hydroxyl group. This reactivity allows the castor oil to easily polymerise, making it a very useful ingredient in paints, dyes, coatings and inks. Moreover, due to the hydroxyl groups, it is used in polyurethanes.

Work is underway on the development of polyols from other, possibly cheaper, plantbased oils (Natural Oil Polyols, NOPs), such as soy, sunflower or rapeseed oil. The possibilities to produce polyols from plant-based oils are virtually limitless, and the most important research questions currently are: 
- How can NOPs with the correct level of reactivity be produced?

- How can the formation of cyclic compounds, which cause unpleasant smells, be prevented?

Meanwhile, NOPs are already being produced and applied on a large scale. Generally, only the polyol component of the polyurethane is bio-based, which means the bio-based content varies between 10 to 70 per cent, depending on the specific application. Since several years, bio-based isocyanates are commercially available, which allow for the production of $100 \%$ bio-based polyurethane. Pentamethylene di-isocyanate (PDI) is an example of a bio-based di-isocyanate that can replace hexamethylene di-isocyanate. According to estimates, the market volume of bio-based polyurethanes is comparable to that of bioPET.

\subsection{Epoxy resin}

Epoxy resins (or epoxies) are a category of thermosetting materials that are mostly used for protective coatings, adhesives and composites. The global market for epoxy resins amounts to some 1.5 million tonnes annually. Almost $75 \%$ of the epoxy resins are produced from bisphenol-A en epichlorohydrin.

The use of bio-based raw materials in epoxy resins focussed on epoxidised natural compounds. Plant-based oils with double bonds such as soy, linseed or castor oil, can be epoxidised. The reactivity and, ultimately, the cross-link density, depends on the number of epoxide groups. Epoxidised plant-based oils are available in excess as they are also used as plasticisers in coatings and varnishes. The advantage of soy oil is that it is cheap. To achieve resins with the desired qualities, maleic or acrylate groups are often introduced in addition to the epoxy groups. Cardanol oil, obtained from Cashew Nut Shell Liquid, contains natural phenol groups and is used in the synthesis of "crosslinkers" for epoxy resins. Also, epoxidised cardanol oil is commercially available.

Epoxy resins with a $20 \%$ bio-based content are currently produced from glycerol, a byproduct from the production of bio-diesel. These resins contain epichlorohydrin from glycerol.

Finally, work is being done to replace the toxic components in epoxies (bisphenol-A) and apply amine functionalised bio-based components. Renewable resources that can replace bisphenol- $A$ include furanes, pine resin, lignin, itaconic acid and isosorbide.

\subsection{Unsaturated polyesters}

Unsaturated polyesters (UP) are polyesters containing double (or unsaturated) bonds. UP-resins are often liquid mixtures of unsaturated polyesters and styrene, where styrene operates as a reactive solvent. This results in a material with excellent properties to be 
used in coatings, adhesives and composites. Similar to thermoplastic polyesters, biobased monomers can be used for unsaturated polyesters.

A number of bio-based UP products (with a bio-based content up to approximately $70 \%$ ) are currently commercially available. These resins contain bio-based monomers such as isosorbide, itaconic acid, castor oil derivates and succinic acid. Research focuses primarily on replacing the reactive solvent styrene in UP-resins.

\subsection{Alternative reactive systems based on fatty acids}

Alkyd resins form significant examples of curing systems. Alkyd resins first appeared on the market in the 1920 s as high-quality coatings. They are thermosetting and produced through co-polymerisation of polyols, organic acids and plant-based oils. The percentage of bio-based raw materials in commercially available alkyl resins is unknown, but, the plant-based oil is bio-based, and this percentage can be as high as $60 \%$.

The use of plant-based oils and fatty acids forms a source of inspiration in the production of bio-resins with a high degree of bio-based raw materials. Resins based in epoxidised plant-based oils and polycarboxylic acid anhydrides sourced naturally form new reactive systems. The bio-based content of this resin system can reach levels of up to $96 \%$. The resin system is less reactive than, for example, epoxy and polyester resins, and must be cured at temperatures higher than $100{ }^{\circ} \mathrm{C}$ to make its use economically profitable. For example: curing at $100{ }^{\circ} \mathrm{C}$ takes several hours, while it takes only one minute at $190{ }^{\circ} \mathrm{C}$.

An alternative system is based on acrylated epoxidised oils that are cured using methacrylic acid if needed in combination with styrene. This system has the advantage of having a relatively low viscosity, but it is still less reactive than epoxy and UP resins and must cure at temperatures over $90^{\circ} \mathrm{C}$.

\subsection{Furan resins}

Furans are cyclic molecules that are produced through the dehydration of sugar compounds such as glucose and fructose. Resins comparable to phenol resins are produced from furfuryl alcohol-these resins are used in the moulding industry and in fibre board materials such as MDF. Developments in the production of biofuels (bioethanol, bio-diesel) have led to a renewed interest in furan derivates, 5-hydroxy methyl furfural (HMF) in particular.

In the previous chapter, we already indicated that furans are a promising group of compounds that can replace the aromatic components in (thermoplastic) polymers. 2.5furan dicarbonic acid (FDCA) in particular has been extensively studied as a substitute for terephthalic acids in polyesters and polyamides. 


\section{Biobased plastics based on natural polymers}

\subsection{I ntroduction}

Plastics from natural origin are polymers that are extracted and sourced from biomass such as wood, corn, wheat, rice and potatoes. Examples include cellulose and starch. Plastics made by micro-organisms are plastics that are produced by bacteria, yeasts or plants. Both the abovementioned plastics are bio-based plastics based on natural polymers. They are discussed in this chapter.

\subsection{Starch}

\subsubsection{Introduction}

Starch is the food storage mechanism in plants and is one of the most common organic compounds. In Europe, $50 \%$ of the available starch is used in food applications and animal feed, $17 \%$ is used in the production of bioethanol and $33 \%$ in the production of non-food products. The main industrial use of starch is in the corrugated board and paper industry, where it is used as an adhesive and as an agent to improve the printability of paper. Other industrial purposes are found in the textile and adhesives industry, pharmaceuticals and cosmetics.

\subsubsection{Raw materials}

Starch is a carbohydrate made up of a large number of glucose units. Starch has two chemical structures: the linear amylose polymer and the branched amylopectin polymer. The amylose/amylopectin ratio varies between plant species. Starch is a relatively cheap raw material obtained from crops such as potatoes, corn, rice, wheat and cassava. The price of starch ranges from $€ 200$ to $€ 600$ per tonne, making it comparable to crude oil. By comparison, at approximately $\$ 50$ per barrel, crude oil costs about $€ 265$ per tonne.

\subsubsection{TPS Products}

Pure starch (native starch) is not a thermoplastic. It cannot be processed through melting without the use of additives or chemical modification, because it degrades before reaching its melting point. The use of these additives increases the price of commercially available starch-based plastics to relatively high levels, between $€ 1,5$ and $€ 4$ per kilo. The most commonly used method to produce thermoplastic starch (TPS) is to process the native starch using suitable plasticisers such as water or glycerine in an extruder. Increased temperatures, sufficient shear and the presence of plasticisers transform the physical structure of native starch, making it suitable for thermoplastic processing. 
Other methods that are deployed to produce starch-based plastics include (partial) fermentation, chemical modification and mixing or blending with other organic compounds. The source (plant species) of the starch influences the properties of the plastics depending on its composition (amylose/amylopectin).

TPS is often mixed with other bio-based polymers to improve specific properties or to expand the application range of the product.Common examples are (co) polyesters such as polybutylene adipate terephthalate (PBAT), polycaprolactone, PLA, PBS, polyhydroxyalkanoate (PHA) and cellulose acetate. The starch content of such TPS blends varies between $30 \%$ and $70 \%$. As many commercially available TPS-blends contain non-renewable or partially renewable polymers, these materials are seldomly $100 \%$ bio-based.

\subsubsection{Processing}

TPS may be processed in in a manner similar to traditional thermoplastic polymers, using processing techniques such as extrusion, injection moulding, film blowing, sheet extrusion (and thermoforming) and extrusion foaming. Processing temperatures vary between $120{ }^{\circ} \mathrm{C}$ and $180^{\circ} \mathrm{C}$. TPS does not need drying prior to processing; water is essential to the thermoplastic processability of the material.

\subsubsection{Properties}

The mechanical properties of TPS range from flexible (comparable to polyethylene; Emodulus $500 \mathrm{MPa}$ ) to rigid (comparable to polystyrene; E-modulus $3000 \mathrm{MPa}$ ). The properties of TPS can be further fine-tuned through the use of fillers such as chalk or talcum, and natural fibres (e.g. flax).

Remarkable properties of TPS are its gas barrier and antistatic behaviour. Thermoplastic starch has a relatively low $\mathrm{CO}_{2}$ and $\mathrm{O}_{2}$ permeability and a high water vapour permeability. This makes it particularly suited for certain food packaging. A disadvantage of TPS in packaging is that the films are not transparent but translucent, somewhat opaque. However, if the product presses against the film, it is clearly visible. Starch is water-soluble, and products made of TPS will slowly disintegrate in water. This property can be put to use in applications where water solubility is a desired property. However, for many uses, the product should be more waterproof. This can be achieved by using TPS blends, or by processing the TPS in multi-layered films.

TPS-based materials disintegrate and biodegrade erapidly in various environments, depending on the blend composition. The materials are not only compostable in composting plants, but also in home- composting or in the soil. 


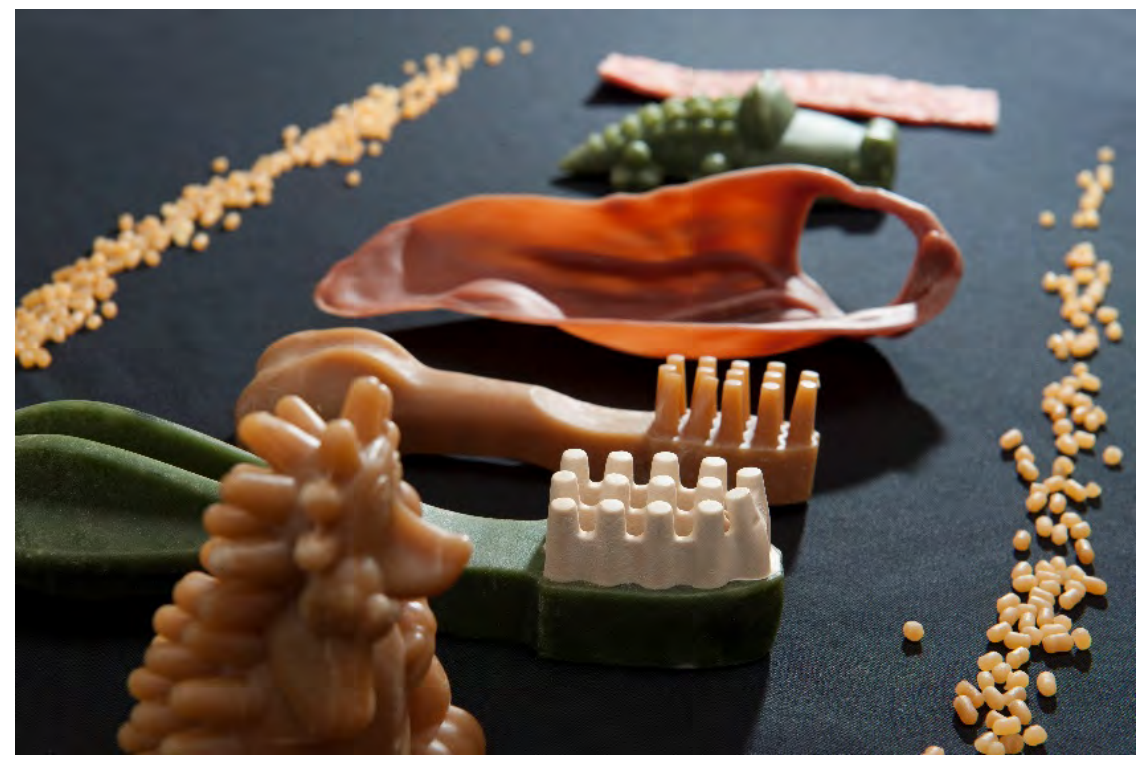

TPS-based vegetarian dog treats (Paragon Pet chews)

\subsubsection{Uses}

So-called loose-fill foam is an important use. During the production of foam chips, the water in starch is used as a blowing agent. TPS blends are also used in films for shopping bags and garbage bags for organic waste. Moreover, TPS is used in disposables such as plates and cutlery. Its biodegradation properties are a distinct advantage in these applications, and, in combination with its high bio-based content, form the main reason for its use.

Examples, where the specific properties of TPS are used, include food packaging where the gas barrier properties are relevant, and edible products made from TPS. Through injection moulding, TPS is processed into vegetarian dog treats shaped as toothbrushes, hedgehogs, bones and so on. In agriculture and horticulture, TPS blends are used in plant pots, tie wraps and mulch films. The use of TPS is cost-competitive in comparison to non-degradable plastics since the plastics need not be removed and there is less waste, which reduces labour costs.

With their wide range of applications, TPS materials are among the most frequently used bio-based plastics with a production capacity of over 300 kilotonnes per annum. 


\subsubsection{Developments}

Future developments in TPS-based materials are the development of $100 \%$ bio-based blends and materials suited for uses with higher demands. Cheaper blends can be made using flour instead of (purified) starch or by increasing the starch content in TPS blends.

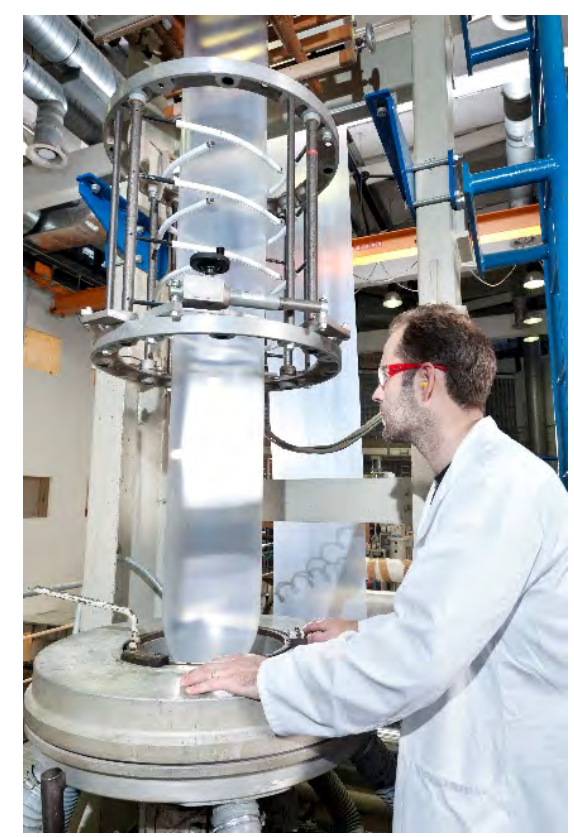

Production of starch-based film

\subsection{Cellulose}

\subsubsection{Introduction}

Cellulose is the most common biopolymer on earth. Approximately $33 \%$ of all plant material is cellulose. Like starch, cellulose is a carbohydrate that is made up of a large number of glucose units. The main difference being that in cellulose the glucose units are connected in a different way, which makes cellulose highly crystalline.

This crystallinity causes cellulose to have a high melting point, which makes it unsuited for thermoplastic processing and insoluble in conventional solvents.

Cellulose-based bioplastics are made from an extremely pure cellulose pulp (dissolving pulp). This pulp is produced from wood (cellulose content 40-50\%) and cotton (cellulose content $90 \%$ ). 
Non-thermoplastic cellulose is used in fibres (rayon, viscose) and films (cellophane); these cellulose materials are known as regenerated cellulose. Thermoplastic cellulose derivatives such as cellulose acetate are mainly used in textile fibres or cigarette filters. However, there is a growing interest in cellulose acetates as a bio-based material for other uses as well.

To distinguish the different types of cellulose polymers, they are described individually below.

\subsubsection{Regenerated cellulose}

Regenerated celluloses are produced from a solution and cannot be processed through melting. Traditional production processes often involve pollutant chemicals such as carbon disulphate $\left(\mathrm{CS}_{2}\right)$. However, much progress has been made in the area of environmentally friendly production methods such as the Lyocell process. Both the expensive raw material (dissolving pulp) and the production process (energy and chemicals) contribute to the high cost of regenerated celluloses.

At the turn of the last century, viscose was the most common synthetic fibre used to replace cotton. In the nineteen sixties, viscose was supplanted by newly developed petrochemical fibres such as nylon and polyester. However, viscose is still used in highvalue applications because it has similar properties and wearing comfort as natural fibres such as silk, wool, cotton and linen. Viscose is ideal in warm and humid climates as it absorbs moisture but allows body heat to pass through.

Cellophane film is used in packaging, sellotape and several industrial applications such as semi-permeable membranes in certain batteries. Its high dimensional stability, as well as its resistance to chemicals, oils and fats, provide a significant advantage over most thermoplastic films. Cellophane has an excellent gloss and transparency and is a rigid material that has excellent dead-fold properties and is therefore ideal for candy wrappers. In new applications, the biodegradable aspect and the fact that the material is $100 \%$ bio-based, is used. Cellophane is often provided with a layer of TPS-based sealant to make the material sealable, which is a prerequisite in many packaging applications.

Barrier films with an excellent oxygen barrier are commercially available. Cellophane film is metallised with aluminium oxide to achieve these properties. Cellophane-based barrier films meet the EN13432 composting standard.

Regenerated celluloses are by far the largest group of industrially used bio-based plastics with a global annual production of 3.5 million tonnes. The focus on bio-based materials has resulted in a renewed interest in cellulose materials, as they are $100 \%$ bio-based and biodegradable. New, more environmentally friendly production processes are currently being developed to produce regenerated cellulose and cut the production costs. 
An increase in new products based on cellophane films is expected, due to the biodegradability of the material.

\subsubsection{Thermoplastic celluloses}

For cellulose to become processable as a thermoplastic, it requires (intensive) chemical modification. Examples include cellulose-esters such as nitrocellulose and cellulose acetate. These cellulose plastics are among the oldest commercially produced plastics.

Cellulose nitrate, or nitrocellulose, was initially produced by treating cellulose with nitric acid. The first moving pictures shown in movie theatres were made on cellulose nitrate film. This practice is obsolete, as the material is highly flammable. It is, however, still used in some explosives and varnishes.

Cellulose acetate is currently the primary thermoplastically processable cellulose derivative and has a global production of approximately 840 kilotonnes per annum. This cellulose-ester is produced by modifying dissolving pulp with acetic anhydride. Other examples of cellulose acetates are cellulose acetate butyrate $(C A B)$ and cellulose acetate propionate (CAP). Although cellulose acetates are renewable, they are not very environmentally friendly as they require quite some energy and chemicals in their production. Cellulose acetate is available in substitution degrees ranging from 2.5 to 3 of the $3 \mathrm{OH}$-groups. This substitution degree influences the biodegradability and solubility of the material. Cellulose diacetate (substitution degree $\sim 2.5$ ) is an amorphous and transparent polymer with excellent optical (gloss), mechanical and thermal properties. The mechanical properties of cellulose diacetate are similar to polystyrene in terms of rigidity, and with polycarbonate in terms of toughness.

Pure cellulose diacetate has a $T_{g}$ of approximately $200^{\circ} \mathrm{C}$, and thus a high heat deflection temperature (HDT).

Cellulose acetate can be processed through conventional techniques such as injection moulding, extrusion, and thermoforming. The polymer is less suited for use in injection moulding machines with a hot-runner system which keeps the polymer in the molten stagelonger periods of time. Plasticisers can be used to improve the processability of the material. Commonly used plasticisers are citrate esters such as triethyl acetyl citrate and triethyl citrate, triacetin and diethyl phthalate. Thermal degradation may occur during processing, especially at higher temperatures.

The most important use of cellulose acetates is fibres for the production of cigarette filters (acetate tow) and textiles. In many plastic applications, cellulose acetate has been replaced by petrochemical plastics. Cellulose acetates are still (or once again) found in high-value uses such as spectacle frames, screwdriver handles, telephones and keyboards. The glossy look and comfortable grip are distinct advantages in these applications. 


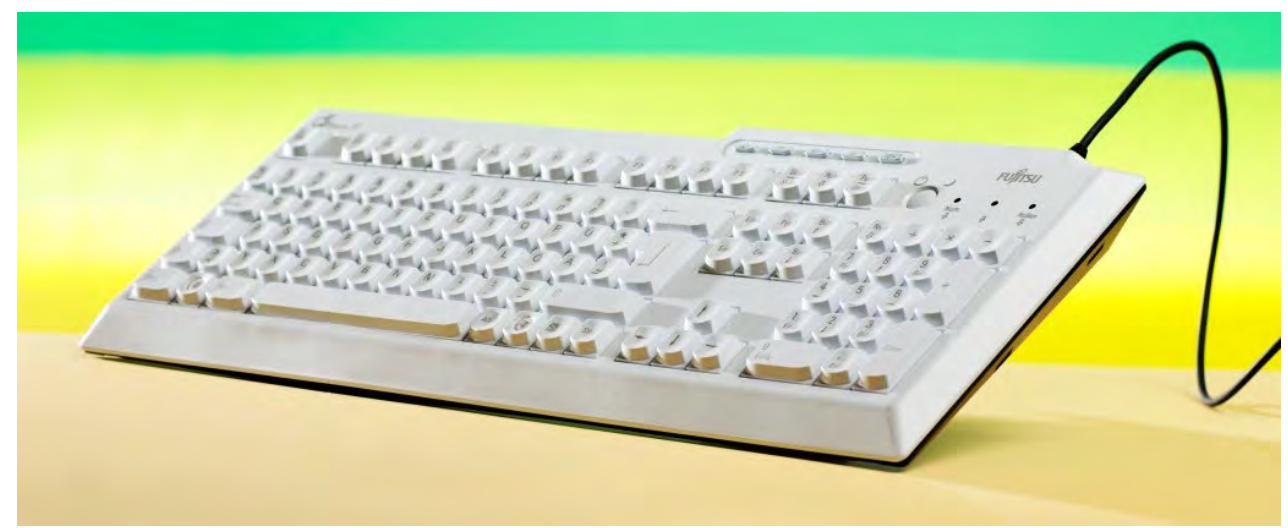

Keyboard based on a cellulose acetate compound (FKuR)

Other uses are lenses, displays, decorative elements (in the automotive industry, for example) and packaging. Cellulose acetate is one of the few plastics that is microwave proof and can hold hot liquids due to its high resistance to heat. Moreover, cellulose acetate is used in disposables such as cutlery, plates and cups.

The main disadvantage of cellulose plastics is the high market price of $€ 4$ per kilo. This hampers large scale use of the product. New developments in the domain of cellulose acetates focus on making blends that make use of the qualities of cellulose acetates (heat resistance and toughness). Efforts to reduce costs by using cheaper fillers are also underway.

\subsection{Bio-based polymers from micro-organisms}

\subsubsection{Introduction}

In the field of polymers produced by micro-organisms, polyhydroxyalkanoates (PHAs) are most frequently discussed, but cellulose too can be produced by micro-organisms. This microbial cellulose is used in niche industries such as wound dressings, due to its high level of purity and high costs. PHAs are the most compelling example because they are a family of polyesters with a wide range of properties and uses.

Polyhydroxyalkanoates are linear aliphatic polyesters. In essence, many polyesters with a very wide variation in properties can be produced. Over one hundred monomer units have been identified as possible components of PHAs. 


\subsubsection{Production}

PHAs may be produced by different bacteria, yeasts or plants. Plants and yeasts must always be genetically modified for this purpose. Examples of micro-organisms for the production of PHAs are Alcaligenes eutrophus or Bacillus megaterium. Glucose, starch, fatty acids or plant-based oils can be used as a feedstock.

During the production process, the micro-organisms must first multiply and then be prompted to accumulate PHAs. The yield ranges from 30 to $80 \%$ of the dry weight of the micro-organism. The key steps in the production process are the efficient conversion of feedstock to PHAs by the micro-organisms, followed by the extraction of the PHA. Much research is still needed to make these steps more efficient, and thus cut the cost of PHAs.

\subsubsection{Processing}

PHAs may be processed using conventional processing equipment. The processing temperatures lie around $160-180^{\circ} \mathrm{C}$. It is advisable to dry the PHAs prior to processing, as thermal degradation may occur at higher temperatures. The low melting strength during processing and the extremely low melt viscosity are disadvantages of PHAs. The most commonly used processing techniques are currently injection moulding, sheet extrusion and thermoforming. Research is being conducted on alternative processing techniques.

\subsubsection{Properties}

The primary commercially available PHAs are poly hydroxybutyrate ( $\mathrm{P} 3 \mathrm{HB}$ and P3HB4HB), poly hydroxybutyrate valerate (PHBV) and poly hydroxybutyrate hexanoate $(\mathrm{PHBH})$. PHAs may have properties comparable to elastomers (rubbery) or highly crystalline polymers with a $175^{\circ} \mathrm{C}$ melting point. Some examples:

- $\mathrm{PHB}$ is a highly crystalline thermoplastic material that is more rigid than PP. It is very brittle, which limits its applicability

- PHBV is tougher and is slightly more rigid than PP (1000-2000 MPa), and has a strain at break of $10 \%$ to $50 \%$

- P3HB4HB and PHBH have mechanical properties such as a strain at break that are similar to those of PP and HDPE

Advantages of PHAs over other biopolymers are their excellent bio-degradability in combination with their high HDT and hydrophobicity.

PHAs are compostable (in home composting also) and biodegradable in anaerobic fermentation plants, soil and even in the marine environment. However, degradation in the sea occurs at a much slower pace than in the ground. The water vapour barrier of 


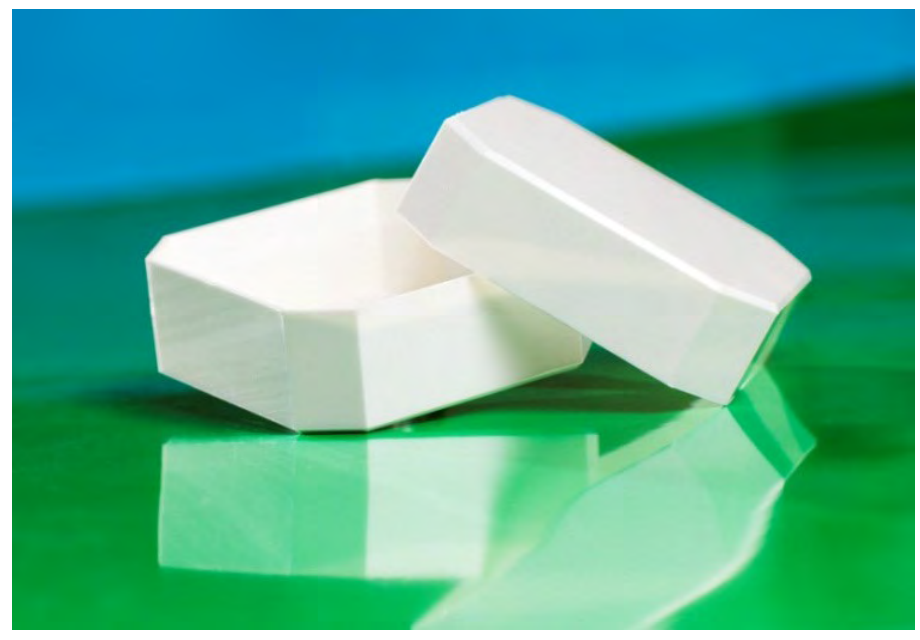

Box made of PHA (Kaneka)

PHAs is relatively high, which offers significant advantages over other bio-based plastics. PHAs are not transparent, which may be a disadvantage in packaging applications.

\subsubsection{Uses}

Application of PHAs in fields where cost is not so much of an issue is the most logical, given the high market price of the material. This includes medical and pharmaceutical uses (screws, surgical plates, stents). In the past, Japan used PHAs in shampoo bottles and credit cards. Currently, PHAs are frequently used in bio-based polymer blends. PHAs can be applied as an impact modifier to improve the impact strength (toughness) of PLA.

\subsubsection{Availability and price}

$\mathrm{ICl}$ was a pioneer in the area of commercial production of PHAs in the nineteen-eighties. At the time, there were limited possibilities for use, due to the high production costs. There is a renewed interest in PHAs at this moment, particularly as a result of the specific properties that set PHAs apart from other commercially available bio-based polymers. The production costs of PHAs have decreased significantly since the introduction in the market by $\mathrm{ICl}$. A further decrease is expected in the future. PHAs are currently offered on the market for prices ranging from $€ 4$ to $€ 5$ per kilo by producers from America, Brazil, China and Japan. Specific PHA (blends) for biomedical purposes cost $€ 10$-15 per kilo.

Although the production capacity is limited to approximately 70 kilo-tonnes per year, there are plans to increase this capacity. The success of these plans is highly contingent 
on market developments, economies of scale, and the use of second-generation raw materials such as lignocellulose or waste streams.

\subsubsection{Developments}

Future developments focus on reducing costs through optimising production processes, larger production plants and simplified downstream processing (isolating PHAs from micro-organisms). There is much research focussing on producing PHAs in wastewater purification plants. In these plants, PHA producing micro-organisms occur naturally, and their numbers could be significantly increased to make a profitable yield of PHA possible. Another interesting development is the production of PHA's from greenhouse gasses like methane and $\mathrm{CO}_{2}$.

The range of commercially available PHA-grades is expected to increase. Through product development and blending with other bio-based polymers materials and products with an excellent price/quality ratio may be developed.

\subsection{Natural rubber}

Natural rubbers are elastic materials (elastomers) that adapt to stretching or pressure but return to their original shape afterwards. This elasticity results from long polymer chains that are (slightly) cross-linked, and which make distortions reversible because they are rubbery under normal temperatures (above $T_{g}$ ).

The indigenous populations of South and Central America were familiar with the use of elastomers. They produced rubber products from the latex of several plants, including Hevea brasiliensis. Rubber produced from the latex of this tree became popular in the mid-eighteenth century in Europe. The discovery of vulcanisation by Charles Goodyear in 1838 marked the breakthrough of natural rubber. Goodyear heated latex with sulphur, which significantly improved the properties of the rubber.

Natural rubber is a product of the polymerisation of cis-1,4-isoprene. Although

polyisoprene can be produced synthetically through the polymerisation of (petrochemical) isoprene, natural rubber from the Hevea tree has retained a large market share. Due to the high molecular weight and the high stereochemical purity, natural rubber is prefered in specific applications, such as surgical gloves, or aircraft tyres. The global production of rubber is approximately 24 million tonnes, of which natural rubber amounts to some $40-45 \%$. Natural rubber is mainly produced in SouthEast Asia.

There are several disadvantages to the dependence on latex of the Hevea brasiliensis as the sole source of natural rubber. The Hevea tree has few genetic variations, making the rubber plantations vulnerable to plagues such as leaf blight. The tree only thrives in very specific climates, which makes it impossible to breed the tree in moderate climates. Moreover, some people are allergic to the proteins in natural latex. 


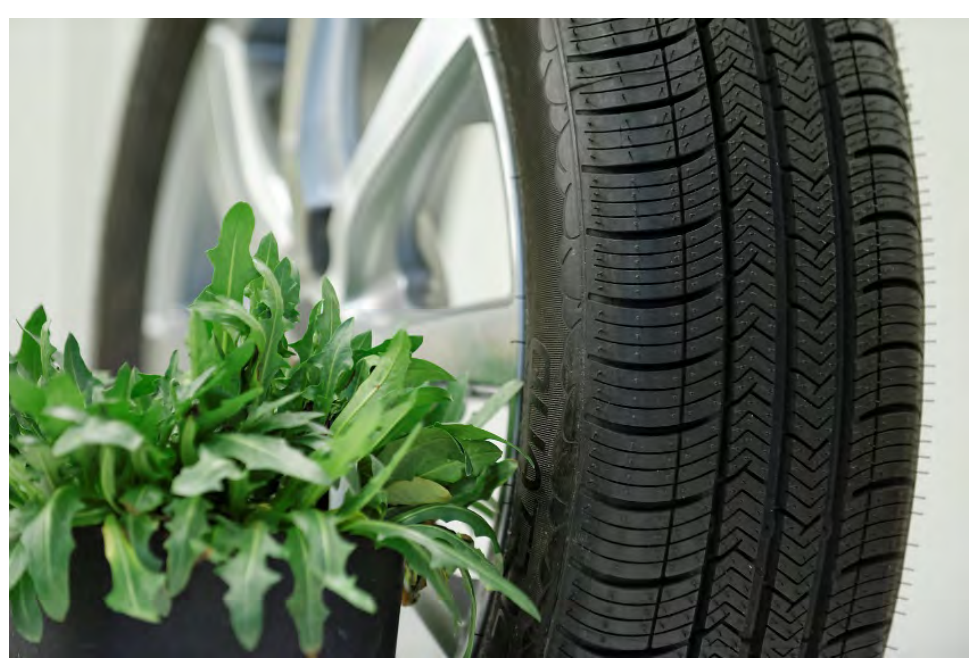

Tread made from rubber of Taraxacum kok-saghyz (Apollo Vredestein)

A search for alternative rubber-producing plants led to the discovery of 2500 other species that produce cis-1,4-polyisoprene, some of which are of good quality. The two plants that appear the most promising as an alternative source of natural rubber are Parthenium argentatum (guayule), a shrub originating in Mexico and Taraxacum koksaghyz (Russain dandelion), which was used in Russia to produce tyres during the Second World War. In addition to the search for alternative sources of natural rubber, biotechnological routes are investigated for the production of isoprenes. These bio-based isoprenes can be polymerised to polyisoprenes. 


\section{Processing bio-based plastics into products}

\subsection{I ntroduction}

The previous chapters discussed the different types of bioplastics, including their properties, processing, applications and availability. This chapter provides additional information on the conversion of biobased plastics into products. It contains information on the possibilities offered by additives, blending and the use of fillers to make bio-based plastic products.

\section{$5.2 \quad$ Additives}

\subsubsection{Introduction}

Besides the development of new polymers, the success of plastics can be largely attributed to additives that improve the properties (such as UV-stability and toughness) of the final products, the processability of polymers (such as lubricants, release agents) or that add properties ( such as colour). In applying these additives to plastics, the nature of the polymer, the specific properties that need enhancing and the desired functionality of the product must be taken into account.

\subsubsection{Additives for bio-based plastics}

Additives developed for PE are equally suited for bioPE, and additives for traditional polyamides can also be used in bio-based polyamides. However, specific additives that target the characteristics of these plastics have been developed for new polymers such as PLA and PHAs:

- Chain-extenders or branching agents (additives used to introduce side-chains) that are used to increase the melt strength of PLA and PHAs

- Nucleating agents to increase the crystallisation speed of PLA and PHAs

- Additives that prevent hydrolysis during processing; many bioplastics are polyesters, and, as such, sensitive to hydrolysis

In addition to their desired function, additives can also negatively impact other properties. Impact modifiers can decrease the transparency of PLA, for example. Several producers have developed impact modifiers that increase the toughness of PLA without affecting its transparency. For bio-based plastics, in particular, the use of additives can affect both the biodegradability and bio-based content. 


\subsubsection{Additives for biodegradable products}

According to the EN13432 standard for compostable materials, all components added to a product in quantities exceeding $1 \%$ of its weight, must be biodegradable. Additives such as impact modifiers are only functional when they make up $5-10 \%$ of the product weight. In order to continue to meet the EN13432 standard, biodegradable impact modifiers must be used. As many polymer processors are only able to use additives in pre-mixed concentrates or masterbatches, specific masterbatches of biopolymers are developed and applied.

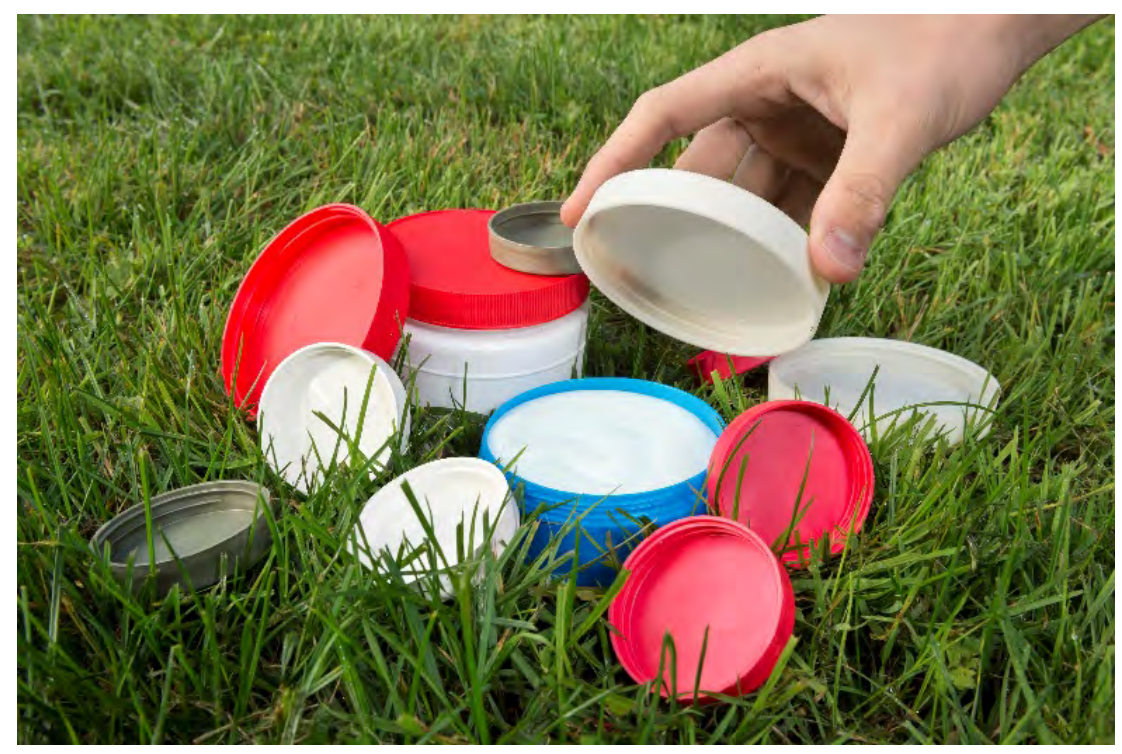

Coloured bio-plastic products

\subsubsection{Biobased additives}

The market also requires new bio-based additives for bio-based plastics that are not necessarily biodegradable. Most additives for biobased polymers are made from fossilbased raw materials. Adding these to a product reduces the bio-based content. This is true for impact modifiers, but even more so for plasticisers, which are sometimes added in amounts of up to $25 \%$.

Examples of commercially available bio-based plasticisers are triacetin (based on glycerol), citrate plasticisers (based on citric acid), castor oil-based plasticisers, linear di-esters such as sebacate esters (based on natural acids) and isosorbide esters. The specific properties make these bio-based plasticisers suited for use in traditional 
polymers such as PVC as well as in bio-based plastics. Moreover, bio-based plasticisers are less harmful to humans and the environment than the frequently used phthalate plasticisers.

\subsection{Blends}

As more bio-based polymers become available, mixing (also known as blending or compounding) becomes an effective way to further enhance and adjust the properties of bio-based plastics. There are two different developments worth mentioning with regard to blends. Efforts are made, on the one hand, to develop biodegradable products and materials, and on the other hand, to develop products with the highest possible biobased content. Blending can affect both the biodegradability and the percentage of biobased raw materials. In both types of products, so-called hybrids are used: a combination of fossil-based polymers and bio-based plastic. Besides, sometimes the one polymer is added to the other, or vice versa. Some examples:

- Blends of starch with PBAT (polybutylene adipate terephthalate). PBAT is biodegradable and compostable according to the European standards but is currently fossil-based

- PBAT is added to PLA to improve toughness and to make the production of tearresistant flexible films possible

- Bio-based plastics such as PLA are added to starch (TPS) to increase strength and modulus as well as water-resistance

- Starch (or PBAT) blends are biodegradable in the soil and can be used as weed growth impairing mulch films. PLA is biodegradable and compostable, but will not degrade in soil

- PLA is added to ABS (Acrylonitrile Butadiene Styrene) and PC (polycarbonate) to increase the bio-based content of computer cases

- PLA and PMMA blends ar miscible and produce plexiglass material with excellent properties and high bio-based content.

These examples illustrate that there are many possible combinations if you consider only biodegradability and bio-based content. Many companies offer these blends or masterbatches. However, the claims they make are not always correct. For example, starch mixed with PE is sometimes said to be biodegradable, and starch with PBAT is said to be fully bio-based. However, choices are also based on desired features and pricing. Different combinations of materials are used for transparent films than for injection moulding, where transparency is not required. PHA, PLA and TPS are bio-based, PBAT and PBS are not, or not yet. In bioplastic blends, TPS and PLA are the cheapest 
components. PLA is also used for its rigidity and transparency. PBAT and PBS are added to improve toughness and increase the HDT. Starch and PHA may be added to improve biodegradability.

\subsection{Fillers}

Since most bio-based polymers are currently more expensive than fossil-based polymers, fillers are often added to reduce the material costs. Fillers can also increase rigidity as well as strength and crystallisation speed. Frequently used mineral-based fillers are chalk and talcum. Organic fillers such as wood flour, natural fibres or even wheat flour are also used. In general, fillers make plastic materials brittle, so that (additional) impact modifiers are required. According to the EN13432 standard, up to $50 \%$ fillers are permitted. Organic fillers can increase the rate of biodegradation.

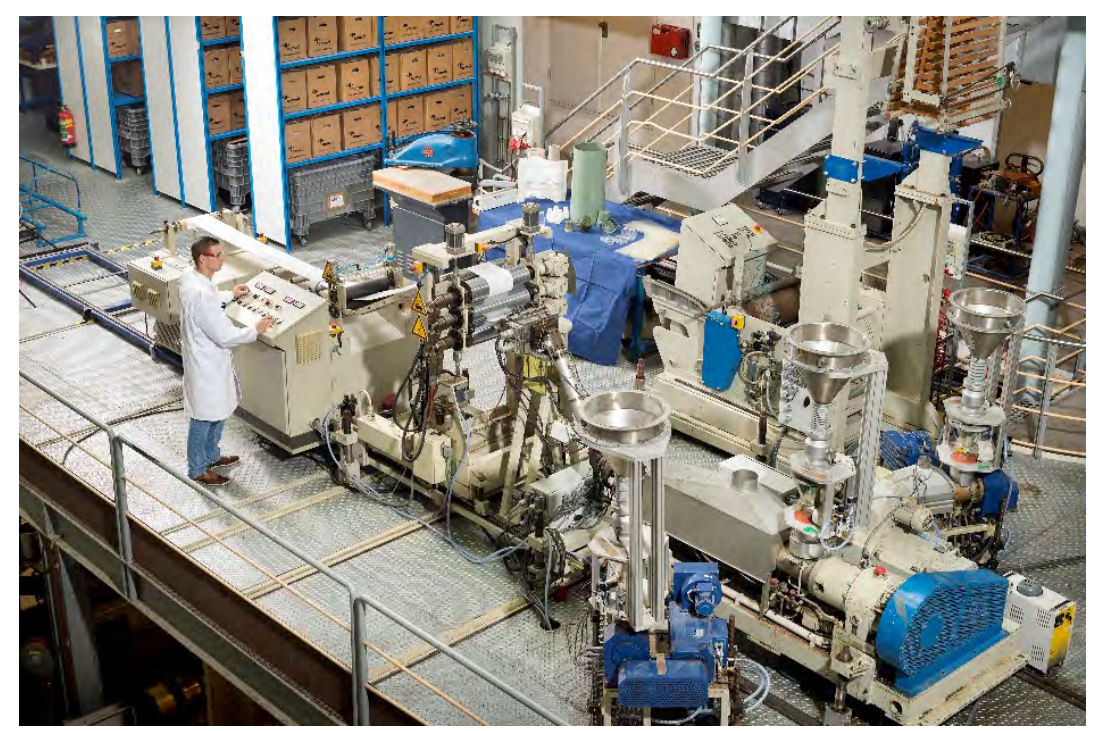

Production of multi-layer bioplastic sheets

\subsection{Product development}

When products based on bio-based polymers are developed, it is essential to distinguish between the drop-in bio-based plastics and "new" bio-based plastics. Drop-in bio-based plastics such as bioPE and bioPET are replacements for PE and PET. Product development, processing, usage up to and including the waste stage are identical. 
However, when new bio-based plastics are used, such as PLA and PBS, a redesign is needed. Although conventional processing equipment may be used, processing conditions will have to be modified. Which conventional plastics can be replaced may be be assessed on the basis of the properties of specific bio-based polymers.

PLA, for example, is an excellent replacement for PS (polystyrene) and sometimes PET (thermoformed trays and cups). Starch-based films can replace (LD)PE, depending on the specific use. Redesign has advantages in terms of functionality. PLA yoghurt containers can be thinner than PS containers because PLA is more rigid. If PE mulch films are replaced by starch-based mulch films that are soil-degradable, also much thinner films can be used. 


\section{Sustainability}

The main link between fossil-based plastics, bio-based plastics, and sustainability is that replacing fossil-based resources with biomass has a positive impact both on climate change and on how we handle waste. Plastic soup, in particular, has been the subject of heated debate over the past few years.

The Ellen MacArthur Foundation has formulated a perspective on the new plastic economy, centred on the production of new plastics from biomass and better recycling.

\subsection{Climate and land use}

Climate change is one of the main reasons for using bio-based plastics. In recent years, several "cradle to factory gate" life cycle analyses (LCA) were conducted on the sustainability of the production of bio-based plastics. These LCAs focus on the environmental impact of bioplastic production from the moment the crop is sown to and including the production of bioplastics in factories. Recent publications generally paint a positive picture when comparing bio-based plastics to fossil-based plastics.

A 2011 study ${ }^{5}$, in which the production of bioplastics and biofuels from fermentable sugars were compared, shows some interesting conclusions. The main research question was what crop could best be used for the production of fermentable sugars, given the limited acreage available, and what product could best be made from it.

The study revealed that in both the production of PLA and bioPE, less non-renewable energy was required than in the production of fossil-based PE and PET. Moreover, in both cases, the production caused lower greenhouse gas emissions. The study also showed that using biomass for bioplastics leads to an increased reduction in greenhouse gas emissions as compared to the use of the biofuel ethanol.

An important distinction is that PLA requires less land than bioPE. This originates in the difference between biomass and petroleum. Petroleum is made up of carbon and hydrogen atoms, while biomass also contains many oxygen atoms and, in some cases, nitrogen. A bioplastic such as PLA that retains quite a few of the plant's oxygen atoms needs fewer raw materials per tonne of plastic produced. It thus scores better in the comparison than a bioplastic such as bioPE, where many of the originally contained atoms are divested into $\mathrm{CO}_{2}$ and water during the production process. In the production of plastics from petroleum, the advantage goes to plastics that are made up of carbon and hydrogen atoms, such as PE, because chemically incorporating oxygen and nitrogen atoms requires much energy.

${ }^{5}$ Sustainability of biobased products; Energy use and greenhouse gas emissions of products containing sugar as a raw material, Harriëtte Bos, Sjaak Conijn, Wim Corré, Koen Meesters and Martin Patel, 2011 , in the 'Green resources' series. 
In addition to greenhouse gas emissions and the use of non-renewable energy, other environmental aspects, such as water use, the emission of acidifying agents and particulates, eutrophication, are relevant. These environmental aspects mainly pertain to agriculture. Compared to fossil-based plastics, bio-based plastics can lead to a higher impact in these impact categories. However, an increase in the sustainability of agriculture can also positively affect the sustainability of bioplastics.

\subsection{Availability of biomass}

A frequently asked question about the use of biomass for the production of bioplastics is whether there is sufficient biomass available, without the production of plastics impacting the global food supply.

\section{Land use estimation for bioplastics 2017 and 2022}

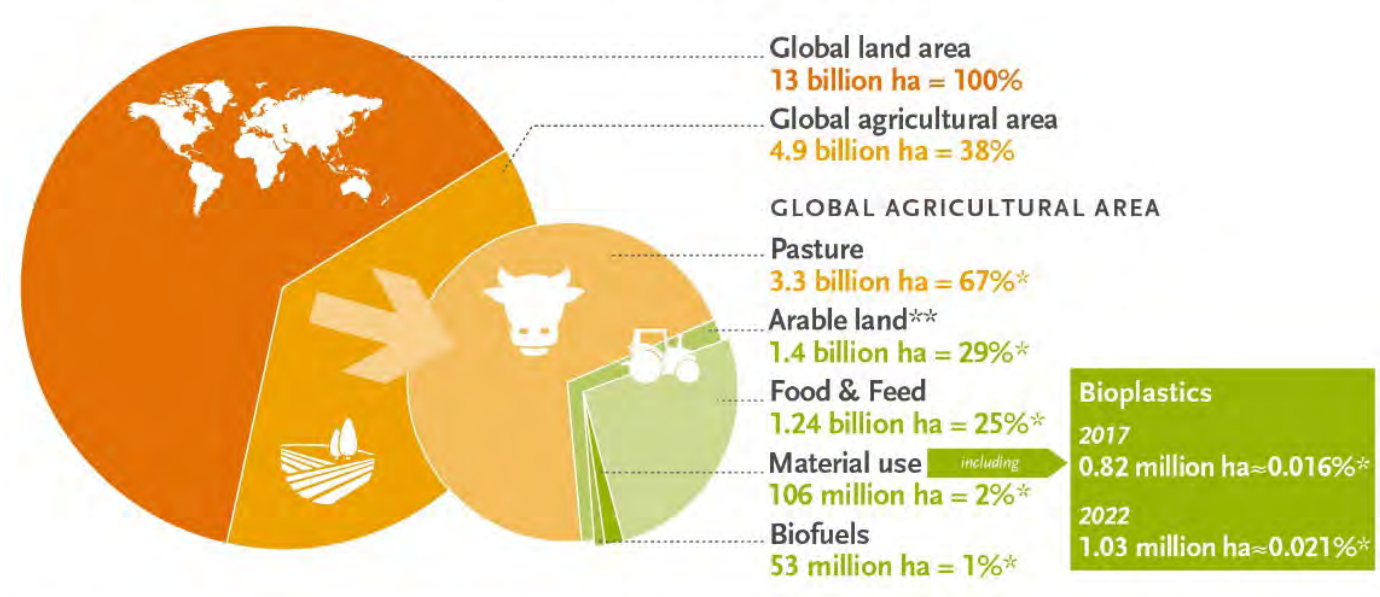

Source: European Bioplastics (2017), FAO Stats (2014), nova-Institute (2017), and Institute for Bioplastics and Biocomposites (2016). More information: www.european-bioplastics.org

Farming lands used for the production of bioplastics as a portion of the total area of available farmlands. (European Bioplastics) ${ }^{6}$

The relationship between the amount of biomass or farmlands that are used in comparison to other applications of biomass, food, animal feed and biofuels is relevant. European Bioplastics ${ }^{6}$ has a clarifying infographic (shown above), which shows that the

${ }^{6}$ https://www.european-bioplastics.org/ 
amount of farmland used for bioplastics is still minimal when compared to other uses, and would amount to no more than a few per cent of the total acreage even if we were to replace all fossil-based plastics with bioplastics. In an interesting recent study Kline et al. ${ }^{7}$ substantiates that integrating the production of food and biofuels can lead to a better basis of raw materials. The outlet to multiple markets may well lead to stabilised prices for biomass raw materials which, in turn, causes intensified production and increased availability of biomass raw materials. The same mechanism naturally also applies to the production of biomass for bioplastics.

\subsection{Waste management and circularity}

The impact on the environment is influenced not only by the source of raw materials for bio-based plastics but also by waste management. Although life cycle analyses show, the latter has a lesser impact. The approach to waste management, and thus the environmental impact, depends on the properties of the materials. In paragraph 1.4 we already discussed the fact that some bio-based plastics such as PLA, PHAs, TPS and regenerated cellulose can also be biodegradable, and that even petrochemical plastics such as PBS, PCL and PBAT can be biodegradable. In this paragraph, we thus discuss biodegradable plastics and bio-based plastics separately.

\footnotetext{
Plastic litter and plastic soup?

It is very difficult to design materials in such a way that they meet all the demands of functional usage, and at the same time disintegrate within a reasonable time in every conceivable environment as soon as they are discarded. Biodegradable materials are therefore not a solution to plastic litter and the issue of plastic soup in the worlds oceans. Moreover, the question is also whether discarding materials is desirable behaviour, and whether society would not prefer to re-use materials. Some sort of collective discipline seems the only short term solution. Creating value for waste can also provide an incentive to its collection. An added complication is that few countries have properly functioning closed waste management systems.
}

\section{Biodegradable plastics}

Many biodegradable plastics are biodegradable in a controlled environment such as a composting or fermenting plant, or a properly functioning back-yard composting heap. Some biodegradable plastics can degrade in soil, or salt or fresh water. During controlled composting, the bio-based plastic is turned into $\mathrm{CO}_{2}$ and water, which can then be used as resources for new plant-based materials. Fermentation results in biogas that contains $\mathrm{CO}_{2}$ and methane $\left(\mathrm{CH}_{4}\right)$. In anaerobic biodegradation outside the fermentation plant's

${ }^{7}$ Keith L. Kline et al. Reconciling food security and bioenergy: priorities for action, GCB Bioenergy (2017) 9, 557-576, doi: 10.1111/gcbb.12366 
Classification of plastics according to biodegradability and source

\begin{tabular}{|l|l|l|l|}
\hline & Petrochemical & Partially bio-based & Bio-based \\
\hline Non- & PE & PET (bio-based ethylene) & PE \\
& PP & PTT (bio-based 1,3-PDO) & Nylon 11 \\
& PS & PUR (bio-based polyols) & Nylon 10,10 \\
& PVC & Nylon 6,10 & \\
& PET & & \\
& PUR & & Natural rubber \\
\hline Biodegradable & PCL & Starch blends & PHAs \\
& PBAT & PBS & $\begin{array}{l}\text { TPS } \\
\text { Regenerated cellulose }\end{array}$ \\
& & & \\
\hline
\end{tabular}

controlled environment, methane has a negative impact, because this greenhouse gas is 25 times more active than $\mathrm{CO}_{2}$. From an environmental perspective, composting is not the ideal method of waste management for biodegradable plastics. The energy content of polymers is mostly lost during the composting process. Energy production, directly through incineration or through the production of biogas as an intermediary, appears to be a better solution. Still, in specific cases, the biodegradation of materials may have an environmental advantage, such as in agriculture, where biodegradable materials may degrade after use (soil covering, clips, pots).

\section{Bio-based plastics}

Bio-based plastic waste that is non-biodegradable can best be processed in the same way as petrochemical polymers. Chemical, material or product recycling is the best option. Reuse is a viable option if the material is sufficiently chemically homogenous. This appears to be a solution for industrial waste, however, this is much more difficult for consumer waste, as separating the different plastic types is technically challenging. Moreover, downgrading usually occurs: the produced plastic is of inferior quality compared to the original. When considering the Ellen MacArthur model for the "new plastic economy", developing better recycling technologies is essential. Especially as $40 \%$ of all plastics are used in packaging, and thus often end up in consumer waste. The better we are able to recycle, the less biomass is needed for new plastics.

\section{Circularity}

Our "plastic economy" is currently linear. On a global scale, only $2 \%$ of the plastic produced is used circularly. PET-based soda bottles are a good example. Besides, some $8 \%$ is reused in lower value applications. These low percentages can be explained by 


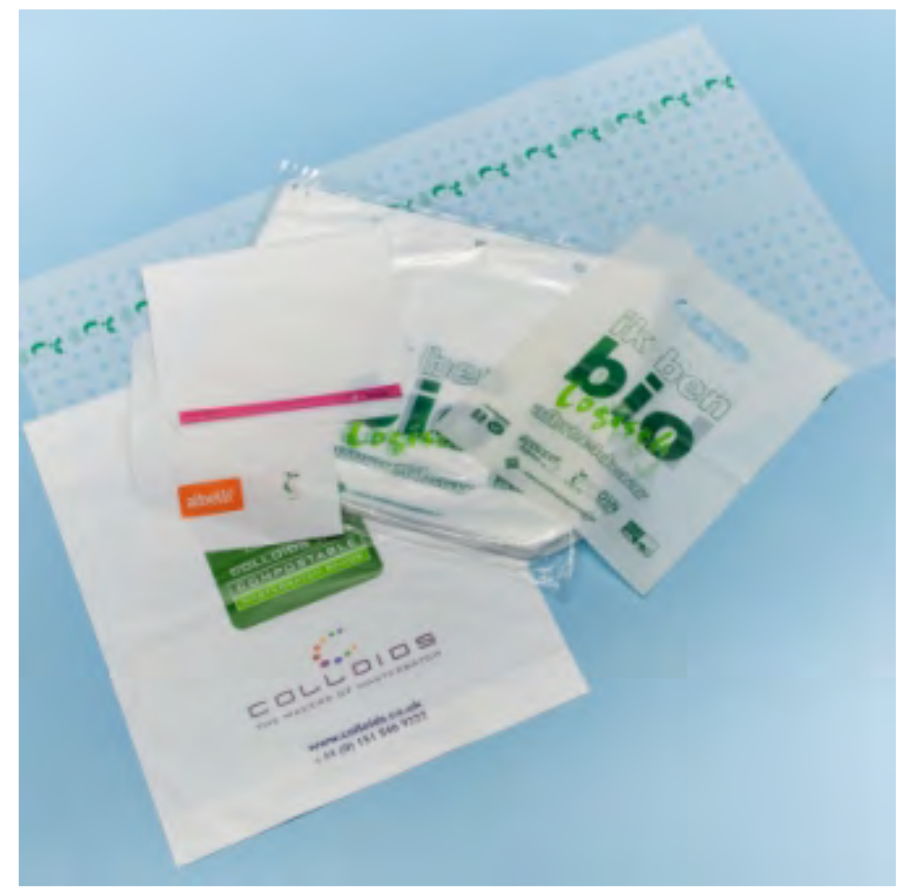

Compostable packaging (Source: Biobased Oerlemans Plastics)

the fact that no more than $14 \%$ of all discarded plastics are collected. A staggering $32 \%$ ends up in the environment, and some $40 \%$ is landfilled. The situation in the Netherlands is better, as we have invested heavily in collecting and reusing packaging materials ( $40 \%$ of all plastics produced are used in packaging). Currently, approximately $38 \%$ of all consumer plastic packaging is collected, and about $20 \%$ of all residual waste subsequently separated. It is estimated that about $6 \%$ of all packaging (both industrial and consumer waste) is thus circularly reused. Approximately $20 \%$ of household packaging is reused for less demanding purposes. In the Netherlands, no plastic packaging waste is landfilled.

A major transition is required for a circular economy, and the question is whether this is viable with our current petrochemical plastics. Bio-based polymers and polyesters, in particular, could play an essential role in the transition towards a circular plastic economy, because they are relatively easy to recycle in a wider range of processes. A non-biobased example of a recyclable polyester is PET. Similar recycling technologies can be applied to, for example, PEF and PLA. 


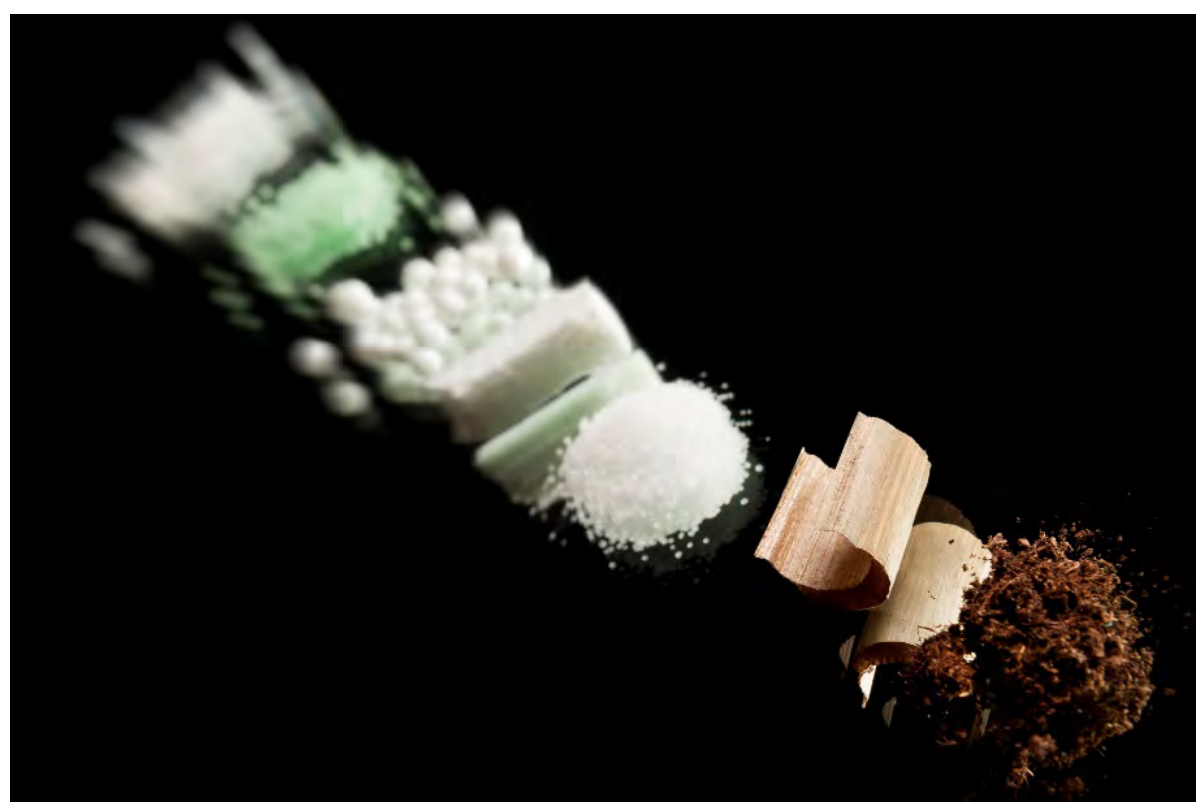

Life cycle of PLA

\section{Conclusion}

As is the case for regular plastics, some form of (mechanical or chemical) recycling is the best option for bio-based plastics. For specific uses, where plastics ending up in the environment cannot be prevented, bio-degradable polymers may offer a solution. In cases where plastic waste is heavily contaminated with organic material (foodstuffs), fermentation with biogas reclamation is an excellent option where biodegradable plastics may offer advantages. 


\section{Market scope and prospects}

\subsection{I ntroduction}

The use of bio-based resources for materials is not new. Wood is still widely used across the globe as a construction material. Approximately $35 \%$ of all textiles are organic (mostly cotton, 30 million tonnes), and human-made cellulose fibres $(6,7$ million tonnes). On a global scale, the production of paper and cardboard (approximately 420 million tonnes in 2018) is greater than that of plastics (some 360 million tonnes in 2019). Other markets for bio-based materials are natural rubber (13.6 million tonnes in 2019) and alkyd paints ( 1 million tonnes).

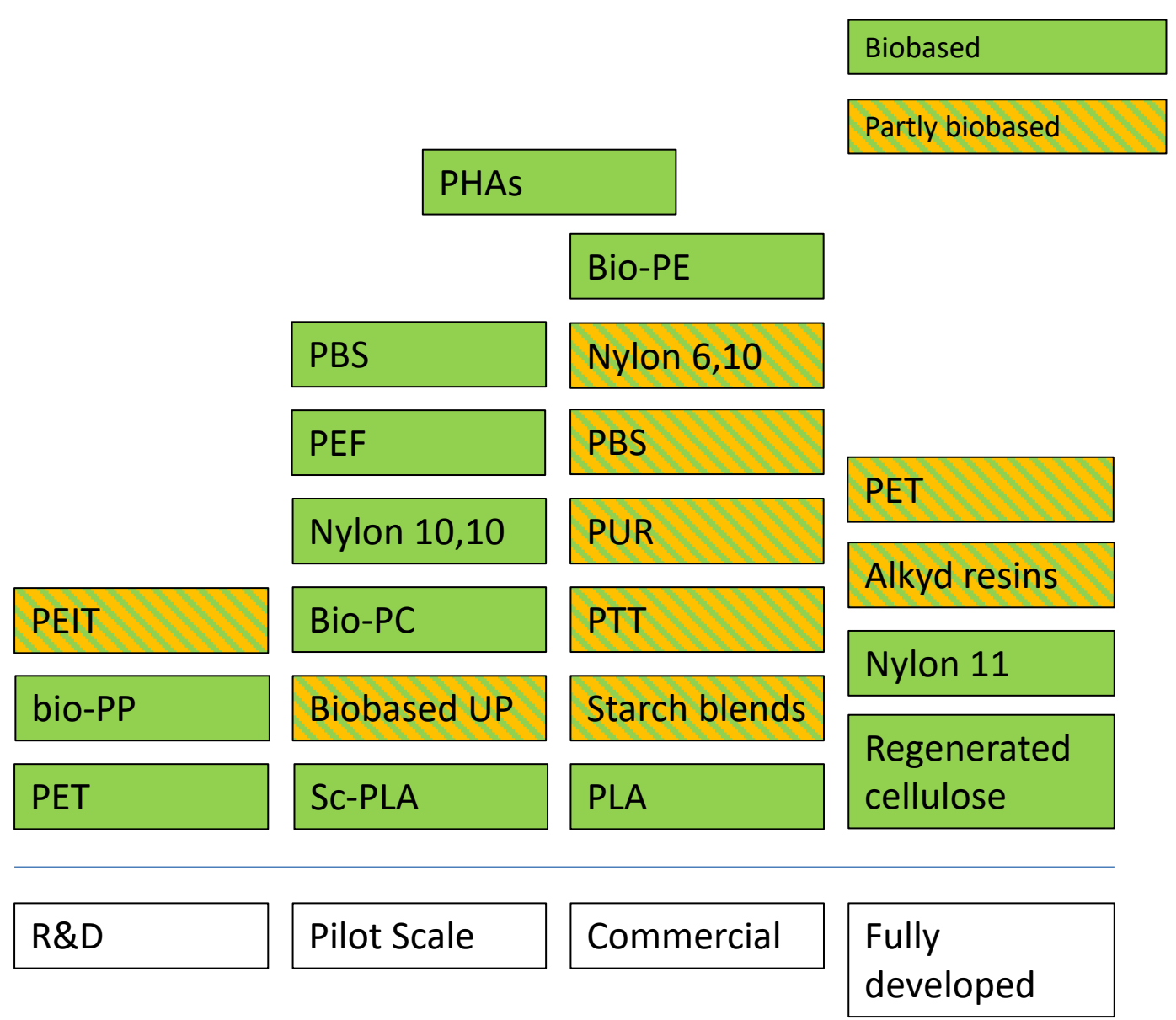

Developmental stages of bio-based plastics 


\subsection{Market supply}

The figure above shows the different development stages of the bio-based plastics discussed in this book. It is worth noting that each development stage is represented by several important products. Moreover, both fully and partially bio-based materials are found in each stage of development. The fact that there are more materials present in the $R \& D$ and pilot stages than in large-scale commercial production stages is no surprise.

\subsection{Market demand}

In the current market, we see that end users, including a surprising number of A-brands, are increasingly willing to pay more for environmentally friendly products, among which bio-based materials.

Large food producers such as Danone, Nestlé and Unilever commit to the Ellen MacArthur model and have announced that all their packaging will be recyclable or bio-based by 2025. Heinz and Coca-Cola have committed to the use of bio-based packaging through support for research and development of biOPET and PEF. Thus, they underline their sustainability promise.

The decision to replace synthetic plastics with bio-based plastics is prompted by the fact that consumers frequently associate packaging with waste issues. The world is currently dotted with plastic bags and islands of plastic waste float in the oceans. In the past decades, civic issues have also risen, particularly with regard to greenhouse gasses. Biobased plastics are often - although not always justified - seen as a step forward compared to synthetic plastics. Leading names in sectors such as the automotive industry (Toyota, Ford) and consumer electronics (Fujitsu, Sony) follow suit for the same reasons.

\begin{tabular}{|l|l|}
\multicolumn{2}{|c|}{ Market prices plastics 2017} \\
\hline Plastic & Market price (€/ kg) \\
\hline PE & $1.25-1.45$ \\
\hline PS & $1.25-1.43$ \\
\hline ABS & $1.90-2.45$ \\
\hline PP & $1.00-1.200$ \\
\hline PC & $3.10-3.70$ \\
\hline TPS blends & 2.50 and higher \\
\hline PLA & 1.80 and higher \\
\hline PHA & $4.00-5.00$ \\
\hline PBS & $3.50-4.50$ \\
\hline PBAT & $3.30-3.70$ \\
\hline
\end{tabular}


The price of bio-based plastics is a decisive factor. The degree in which the purchase price fluctuates is relevant, and the raw materials are cost-sensitive. This stimulates the development of bio-based plastics. Over the past fifteen years, oil prices fluctuated heavily. The price of many bio-based resources such as sugars are traditionally more stable and show little or no increase. This has remained so over the past fifteen years when compared to oil prices, although world market price developments show that agroresources can not escape the general increase in prices. However, in terms of availability as a result of international conflict, the price of oil appears to fluctuate more heavily than that of bio-based resources. How this will develop in the future remains to be seen. The price trend of plastics shows that there is still a difference in price between traditional (cheaper) petrochemical plastics and (relatively expensive) bio-based alternatives. This is one of the reasons why the technology for the production of biobased plastics has not yet been fully developed.

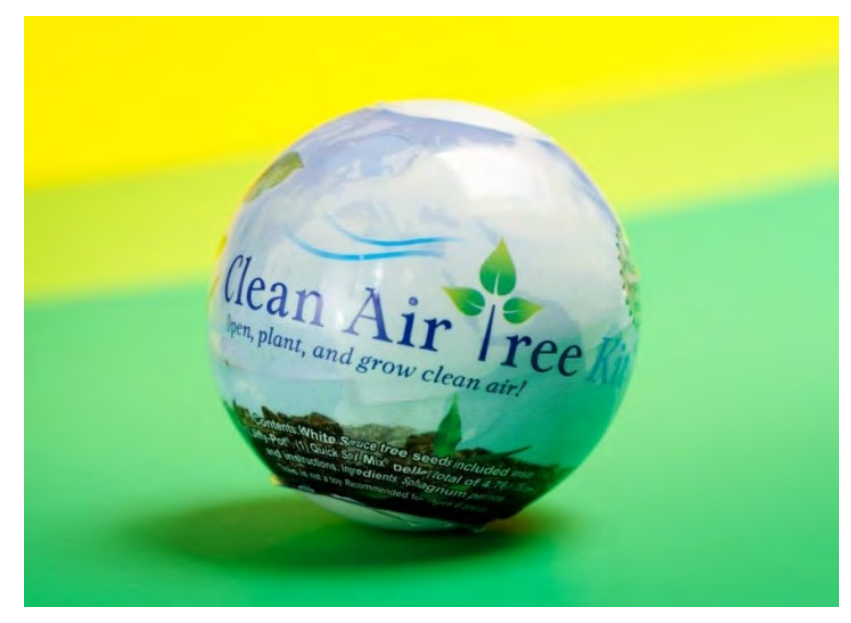

Packaging made from various biodegradable plastics

Cutting costs in the production process, as well as developing technologies to utilise (cheaper) wood-based biomass efficiently as a resource, is expected to lead to lower prices. Bio-based plastics are produced on a relatively small scale. As soon as there is large scale production, the pricing will change. Advantages of scale and solving 'infant issues' will cause prices to drop. The scientific basis for the production of bioplastics is rapidly growing. Chemical catalysis, separation technologies, and industrial biotechnology will develop rapidly. These technologies are crucial to the production of bio-based monomers from non-food resources. 


\subsection{Government policy}

All large economies have legislation that deal with issues related to the production and consumption of plastics. Its main goal is to reduce the amount of waste through recycling and by limiting the use of plastic bags and disposables.

There are currently no specific directives in the EU to promote the use of bio-based plastics and chemicals. In contrast, in the United States of America, the federal government assumes the role of launching customer. Through the 'Bio-preferred' programme, bio-based products are prefered over traditional plastic products in the federal procurement programme. The underlying assumption being that if the government

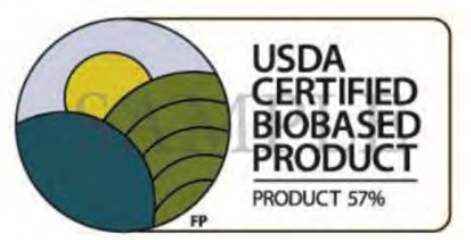
buys bio-based products, this will stimulate sales. This, in turn, boosts production and motivates other businesses to buy these products. Only products featured on the official lists are considered. These products are tested for their bio-based content and sustainability. The ASTM-Standard 6866 (American Society for Testing and Materials) is used to determine the bio-based content, which is currently based on the number of bio-based carbon atoms. This number can easily be determined using the carbon-14 method.

In the EU, directives on packaging, packaging materials and waste disposal are essential. To date, the legislation focuses on closing the materials cycle. There is less focus on greenhouse gas emissions and reducing the influence of the life cycle (energy use and other emissions). Nonetheless, these issues are included in the packaging tax in the Netherlands.

Most member states tax waste production. Many countries also tax producers of electrical and electronic equipment. Compostable products are less heavily taxed. There

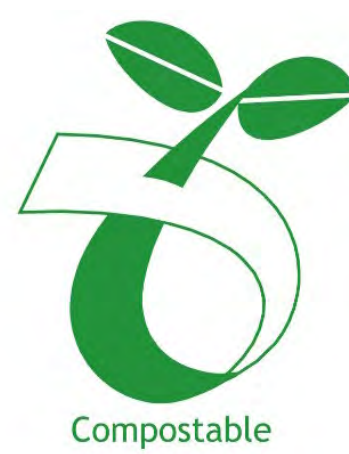

is legislation requiring materials in certain products to be biodegradable or compostable. The European CEN-standard (EN13432) for compostability covers packaging waste. Asia (Japan) and America (ASTM) have similar standards. Products that meet these requirements are eligible to use the logo shown here. Products with this logo may be disposed of as organic waste.

Still, products that are certified compostable are not always accepted. Because composting installations have changed significantly over the last 25 years, and their composting standard still suffices, and whether products that meet this standard decompose sufficiently fast in the current composting plants. Recent research has shown that 
certified products decompose fast enough, also under the presently applied practical conditions (see footnote 2 ). There is also the issue of where compostable products offer an advantage (organic waste bin liners, teabags and coffee pads, fruit stickers ...). These products, in particular, should be aceepted in the organic waste stream. Products such as compostable pens or shoe soles ought to be discouraged.

\subsection{Future perspective}

From a technical perspective, almost all current synthetic plastics can be replaced by bio-based alternatives ${ }^{8}$. Whether or not they will be, depends on the demand. For biobased plastics, it is of importance that the current trend in specific demand for bio-based plastics will continue to grow. The demand is, naturally, contingent on the supply and (production) costs, which, in turn, depend on the available production capacity, technology and investment opportunities. The Ellen MacArthur model of "the new plastic economy" is a stimulant for bio-based plastics.

With regard to the available materials within the bio-based plastics market (see the figure on page 53), we see that these products are proven and ready to move up a development stage as soon as there is sufficient demand and investment capital. More activity in the R\&D stage is expected. Thus, there is reason to believe that there will be rapid developments in the foreseeable future.

Many new factories are the first of their kind, and many technologies are at the start of their learning curve. The launch of new bio-based plastics appears to be in its infant stages. The market for bio-based plastics has grown to 2,1 million tonnes per year in 2019, and is expected to grow slowly towards 2,4 million tonnes in 2024.

\footnotetext{
${ }^{8}$ Green building blocks for biobased plastics, Paulien Harmsen and Martijn Hackmann. In the 'Green resources' series, 2012.
} 


\section{Reflection}

Recent macro-economical developments show that it is very difficult to predict the future. A crisis or economic boom can have devastating or stimulating effects on a growth market. However, it is safe to say that the following aspects are relevant in the further development of the market for bio-based plastics:

\section{Dependence on raw materials}

Agro-resources such as starch and sugar are traded freely. Given the total production volume, the portion that is used for the production of bio-based plastics is generally small. Dependence on a single resource or production location forms a potential threat. However, if cellulose-rich resources can be used in second-generation technologies, the possibilities are almost endless.

\section{Lowering production costs}

For certain materials, such as bio-based PE, nylon 11 and cellulose films, the development is not so much in improving the final product as in more efficient, environmentally friendly and cheaper methods of production. Many bio-based polymers are currently more expensive than their competitors. Technical developments, the use of cheaper resources and increasing the scale of production can solve this. Inspiring in this regard are the examples of bio-based epoxy resin and bio-based PUR. Cutting costs is the main incentive to transition to bio-based resources for these materials.

\section{Broader use}

Plastics in all shapes and forms are used for specific markets. If a bio-based plastic is identical to its synthetic twin (bio-based PE, for example), users will not experience any issues. In all other cases, newcomers will have to prove their worth (PHAs for packaging, for example). The improvement in material properties of PLA over the last few years illustrate that much is still possible.

\section{Recycling and circularity}

Plastics will increasingly have to be recycled or repurposed in high-level applications. This is true for both bio-based and fossil-based resources. This poses challenges, but also creates opportunities for the development of new products. Laminate packaging, such as barrier films and PET-trays suited for closing with top seal films are relevant examples. These products are difficult to recycle mechanically, but if produced from biodegradable materials these composite products can easily be recycled organically. 


\section{References}

The following publications were used in this book:

Shen, L., Haufe, J., Patel, M., (2009) Product overview and market projection of emerging bio-based plastics, PRO-BIP 2009, Utrecht University.

Ravenstijn, J., (2010) The state-of-the-art on Bioplastics; products, markets, trends and technologies.

World Economic Forum and the Ellen MacArthur Foundation, The New Plastic Economy (2017)

Van den Oever, MJ H., Molenveld, K, Bos, HL, van der Zee, M. Bioplastics facts and figures (2017).

Bos, HL, Meesters, KPH, Conijn, SG, Corré, WJ, Patel, MK., Sustainability aspects of biobased applications (2010)

Bos, HL, Meesters, KPH, Conijn, SG, Corré, WJ, Patel, MK., Accounting for the constrained availability of land: a comparison of bio-based ethanol, polyethylene, and PLA with respect to non-renewable energy use and land use, Biofuels, Bioprod. Bioref.

6: 146- 158 (2012)

European Bioplastics, Bioplastics Market Data (2017)

Molenveld, K, Van den Oever, MJ A. Biobased Packaging Catalogue (2015)

Bolck, C, Ravenstijn, J. Molenveld, K. Biobased Plastics 2012 (2011) 


\section{Glossary}

\section{Acrylated}

Acrylating is the process of adding an acrylate group to a molecule $\left(\mathrm{CH}_{2}=\mathrm{CHOO}-\right)$.

\section{Amorphous}

An amorphous polymer (or an amorphous part of a polymer) lacks an ordered (crystalline) structure. At a temperature below the solidification threshold (or $T_{g}$ ), the polymer is in a frozen, glass-like state, while above this threshold it changes from rubbery to syrup-like to liquid depending on the temperature. Amorphous polymers/plastics are generally transparent. PMMA (plexiglass) is an example.

\section{Blowing agent}

A blowing agent is a chemical material or propagating gas that is used to foam a polymer.

\section{Blending}

A polymer blend is a mixture of at least two polymers that, together, form a new material with different properties.

\section{Branching agents}

Branching agents are additives that are used to add side chains to (linear) polymer chains.

\section{Bulk polycondensation process}

A polycondensation process is a chemical reaction that transforms monomers into a polymer through the splitting off of a small molecule such as water or methanol. Polymers such as polyesters, polyamides or polyethers are often produced through polycondensation reactions. If the process takes place without an added solvent for the monomers but is based on pure (molten) monomers, this is considered a bulk polycondensation process.

\section{Cellophane}

Cellophane is a transparent film based on regenerated cellulose. Cellophane is bio-based as it is produced from renewable resources.

\section{Chain-extenders}

Chain-extenders are additives that contain 2 or more reactive groups that are able to link 2 or more polymer chains together. 


\section{Composite}

A composite is a material that is made up of several components. This phrase often refers to fibre-enhanced plastics.

\section{Compounding}

Compounding or extrusion compounding is the process through which one or more polymers are mixed with additives, resulting in a plastic compound.

\section{Co-polyesters}

Polyesters are polymers in which the monomers are linked through ester linkages, for example, through the combination of di-acids and diols. If an additional diol and/or diacid is added to the mix of diol and di-acid, this is referred to as co-polyesters. PEIT, made up of PET with isosorbide as an additional diol, is an example of a co-polyester.

\section{Co-polymerisation}

Co-polymerisation is the building up of polymers from two or more types of monomers.

\section{Crystallinity}

The crystallinity of a polymer is the degree in which the polymer contains crystalline (ordered) phases. Polymers are never $100 \%$ crystalline, but semi-crystalline. Semicrystalline materials have a melting point $\left(T_{m}\right)$ in addition to a glass transition temperature $\left(T_{g}\right)$. Contrary to amorphous polymers, they have good mechanical properties above the glass transition temperatures.

\section{Dissolving pulp}

A dissolving pulp (or dissolving cellulose) is a cellulose pulp with a very high cellulose content ( $>90 \%$ ). Dissolving pulp has unique properties such as a high level of whiteness and uniform molecular weight distribution. It is used in the production of cellulose derivatives such as cellulose acetate and regenerated celluloses (cellophane, rayon).

\section{Dubble bonding}

A double bond is a chemical bond between two atoms involving two common electron pairs. A chemical compound with a double bond is referred to as an unsaturated compound. Unsaturated fatty acids are an example of unsaturated compounds.

\section{Elastomers}

Elastomers are elastic materials whose key property is that they return to their original shape after forced distortion. 


\section{E-modulus}

Elasticity modulus E (also known as Young's modulus), is a material property that is used to express the degree of stiffness of a material.

\section{Epoxidised}

Epoxidising is the process of adding an epoxide group. An epoxide is a cyclic ether with only thee ring atoms. Epoxides are more reactive than other ethers.

\section{Epoxy resins}

An epoxy is a thermosetting resin that can be used to produce composites. It is a twocomponent resin (adhesive) and is used for many purposes, both industrial and domestic. Epoxy can be applied as a coating, or in combination with (glass) fibres.

\section{Extrusion}

Extruding is a forming technique through which a molten polymeris pushed through a die containing one or more complexly shaped holes, that provide the shape of the rod material. This may be a solid or hollow profile.

\section{Extrusion foamng}

This is the fabrication of a foamed product by means of extrusion with a blowing agent added to the molten polymer. Upon leaving the extruder the polymer foams due to the pressure outside the extruder being lower than the pressure within.

\section{Fatty acids}

Fatty acids are organic acids containing a chain of at least 2 carbon atoms and a carboxyl group $(\mathrm{COOH})$. Fatty acids are found in lipids. A lipid is a compound of glycerol and 3 fatty acids. Well-known fatty acids are oleic acids, stearic acid, linoleic acid and palmitic acid.

\section{Fermentation}

Fermentation is the transformation of biological materials through the use of enzymes (or bacteria, cell cultures or fungi) in the presence of oxygen (aerobic) or the absence of oxygen (anaerobic). This method is used in the biochemical industry, where biological products are made.

\section{Film blowing}

Film blowing, also known as blown film extrusion, is a particular technique for making films. A very thin walled tube is extruded, which is then inflated with air, which creates 
a huge plastic balloon in a continuous process. Once cooled, the film is rolled and, if needed, cut, into plastic bags, for example. Products made by this method include plastic bag and films.

\section{Glass Transition Temperature}

The glass temperature $\left(T_{g}\right)$ is the temperature at which an amorphous solid such as glass or polymer solidifies upon cooling or softens upon heating. Glass transition temperatures are particularly relevant in polymers. Although some polymers (such as polyethylene) can also form (semi) crystalline solids, most are unable to undergo a steady accumulation of their molecules in a crystal lattice. Therefore, they remain liquid until below their actual melting point. At lower temperatures $\left(T_{g}\right)$ they solidify, a process that restricts the movement of polymer chains.

\section{Heat deflection temperature (HDT)}

The HDT is the temperature at which a polymer or plastic deforms under applied stress. The HDT is an essential property within the design of plastic products. The HDT is sometimes referred to as the maximum usage temperature and is determined according to a procedure described in the ASTM D648 standard.

\section{Hydrogenation}

Hydrogenation is the adding of hydrogen to molecules in a substance, without causing it to split off an additional substance. Unsaturated compounds become saturated through hydrogenation.

\section{Hydrolysis}

Hydrolysis is the splitting of a chemical compound through addition of water. The ester compound ethyl acetate, for example, decomposes into its components acetic acid and ethanol in water. Hydrolysis may be seen as the opposite of a condensation reaction with the water splitting off.

\section{Hydroxyl group}

A hydroxyl group is a functional group consisting of an oxygen and a hydrogen atom that is attached to the molecule through the oxygen atom. It is also known as an $-\mathrm{OH}$ group or an alcohol group. 


\section{I mpact modifier}

An impact modifier is a rubbery or elastomeric material added to a polymer material to improve its impact characteristics. The impact properties are the resistance to breakage under suddenly applied force (impact).

\section{Injection moulding}

Injection moulding is a forming technique that is applied in thermoplastic (meltable) polymers. During the process, a polymer is molten and injected into a mould in the desired shape of the ( 3 dimensional) product. In cooling, the polymer solidifies and forms a product. Injection moulding is the most commonly used technique for plastic parts.

\section{Loose-fill foams}

Loose-fill foams are the loose fillers used to fill up empty spaces in packaging. These foams are traditionally made from polystyrene. Loose-fill foams made from (corn) starch are $100 \%$ biodegradable and can therefore be composted. The production requires little energy and no chemicals, just water.

\section{Melt strength}

Melt strength measures the elongational viscosity and is defined as the maximum tension that can be applied to a melt without it breaking. The melt strength of polymers is relevant in film blowing and fibre spinning. The melt strength of a polymer can be improved by introducing side chains in the polymer.

\section{Nucleating agents}

A nucleating agent is an additive that provides starting points for the formation of crystallites in a molten polymer.

\section{Plasticisers}

Plasticisers are compounds that soften plastics. If a plasticiser is added to plastic such as PVC (without plasticiser used for hard PVC pipes), the $T_{g}$ is lowered, and the plastic becomes rubbery (PVC hoses, vinyl flooring). Plasticisers are often esters. Well-known plasticisers include phthalate esters such as di-octyl phthalate (DOP) and di-butyl phthalate. Plasticisers are not attached to the polymer and may migrate from the plastic to end up in the environment. 


\section{Rayon}

Rayon is a human-made regenerated cellulose fibre. Rayon is bio-based because it is produced from renewable resources, and it is a semi-synthetic fibre. In the textiles industry, rayon is also known as viscose or artificial silk.

\section{Regenerated}

Regenerated cellulose such as cellophane and rayon are chemically identical to cellulose and are made from dissolving pulp through a chemical process (the viscose process or the new lyocell process).

\section{Ring-opening polymerisation}

A ring-opening polymerisation creates a polymer from cyclic compounds. A catalyst breaks the cyclic bonds, which creates a ring-opening of the next monomer. This causes a chain reaction and thus a polymer. PLA (polylactic acid) is an example of a polymer made from lactide through ring-opening polymerisation.

\section{Spinning fibres}

Fibres are spun from a liquid state. In thermoplastic polymers, this is a melt, and in nonmeltable polymers (such as celluloses) a solution. The liquid is pushed through a spinnerette (a die with tiny openings). Through cooling or evaporation of the solvent, the polymer solidifies and forms a thin fibre.

\section{Stabilisers}

Polymer stabilisers are added to polymers to prevent unwanted reactions such as oxidation and chain rupture, that may result from, for example, exposure to UV light or high temperatures.

\section{Stereo complexes PLA (sc-PLA)}

Sc-PLA is formed from a mixture of PLLA and PDLA. Its melting point lies around $230^{\circ} \mathrm{C}$, which is much higher than the melting point of PLLA or PDLA $\left(170^{\circ} \mathrm{C}\right)$.

\section{Thermoforming}

Thermoforming or vacuum forming is a technique in which thick plastic films $(0.2-2 \mathrm{~mm})$ are shaped to make products. The material is heated before being shaped. Typical examples include plastic cups, plant pots and thin plastic containers.

\section{Viscose}

Viscose is a syrupy organic solution used in the production of rayon fibres and cellophane. Viscose is also used as a synonym for rayon. 


\section{Colophon}

\section{Biobased Plastics 2020}

Karin Molenveld and Harriëtte Bos (Wageningen Food \& Biobased Research)

Translated to English by Meira van der Spa.

The translation to English was supported by the project BLOOM, which aims at boosting the European citizens' knowledge of the bioeconomy and is funded by the European Commission under the Horizon 2020 Framework Programme, Grant Agreement n. 773983.

(c) 2020 All rights reserved

Wageningen Food \& Biobased Research

ISBN: 978-94-6395-610-9

DOI : https://doi.org/10.18174/534587

Printed by: Propress, Wageningen

Wageningen Food \& Biobased Research

Bornse Weilanden 9

Postbus 17

6700 AA Wageningen

https://www.wur.nl/wfbr

Do you have relations interested in this book? Please let us know.

This publication was made possible by the TKI-BBE and the policy supporting research theme Biobased Economy (BO-20.12), funded by the Ministry of Economic Affairs and Climate Policy. It is the $21^{\text {st }}$ in a series of publications on the use of agro-resources and side streams in safe and healthy products for consumer and industrial markets (see www.groenegrondstoffen. $\mathrm{nl}$ and www. biobasedeconomy. $\mathrm{nl}$ ). 


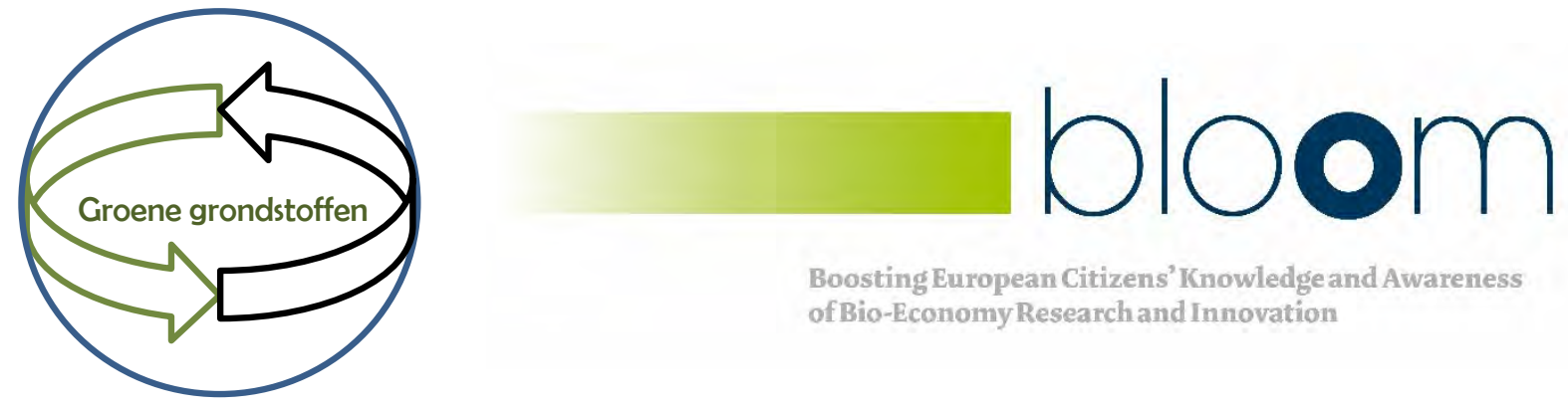

Boosting European Citizens' Knowledge and Awareness of Bio-Economy Research and Innovation 